\title{
Inference on Vertical Contracts between Manufacturers and Retailers Allowing for Nonlinear Pricing and Resale Price Maintenance
}

\author{
Céline Bonnet* Pierre Dubois ${ }^{\dagger}$
}

First Version: April 2004. This Version: December 2008

\begin{abstract}
A methodology is presented allowing manufacturers and retailers vertical contracting in their pricing strategies on a differentiated product market to be introduced. Using retail scanner data on bottled water produced by manufacturers sold at retail chains in France, we estimate a structural demand and supply model allowing for non linear pricing between manufacturers and retailers. Using price-cost margins recovered from estimates of demand parameters both under linear pricing models and two part tariffs contracts with or without resale price maintenance, and performing nonnested tests among different supply models, we select the best supply model for this industry. We find it to be the case that manufacturers use nonlinear contracts, in the form of two part tariffs with resale price maintenance. We use the estimates of this model to obtain brand-retail level marginal costs. We then perform counterfactual policy simulations that, for example, restrict the use of these vertical contracts and assess welfare effects under alternative counterfactual supply side scenarios.
\end{abstract}

Key words: vertical contracts, two part tariffs, double marginalization, resale price maintenance, competition, manufacturers, retailers, differentiated products, water, non-nested tests.

JEL codes: L13, L81, C12, C33

\footnotetext{
*Toulouse School of Economics (GREMAQ, INRA)

${ }^{\dagger}$ Toulouse School of Economics (GREMAQ, INRA, IDEI)

${ }^{\ddagger}$ We thank very much the Editor (Ariel Pakes) and two anonymous referees for helping us improve substantially this paper. We thank M. Simioni, F. Berges-Sennou, S. Berto Villas-Boas, C. Bontemps, P. Bontems, Z. Bouamra-Mechemache, M. Ivaldi, B. Jullien, P. Lavergne, T. Magnac, V. Réquillart, P. Rey, J. Tirole and T. Vergé for useful discussions as well as seminar participants at the London School of Economics, North Carolina State University, University of Toulouse, University of Cergy, GATE, University of Lyon, CREST LEI, the Jornadas de Economia Industrial (Bilbao), the EARIE conference in Porto and the CEPR Conference on Applied Industrial Organization in Munich, the European Economic Association Congress in Vienna, and the Canadian Economic Association Meeting in Montreal.
} 


\section{Introduction}

Vertical relationships between manufacturers and retailers seem to be becoming even more prevalent in the supermarket industry, especially in food retailing. Competition analysis and issues related to market power on some consumer goods markets should involve the analysis of competition between producers but also between retailers and the whole structure of the industry. Consumer welfare may depend on these strategic vertical relationships, in the form of linear or non-linear contracts between manufacturers and retailers. The goal of this paper is to empirically estimate a structural model allowing linear pricing and particularly non-linear contracts and to investigate the effects of policies that restrict non linear vertical contracts among multiple manufacturers and multiple retailers. We extend previous literature by not only allowing horizontal retail and horizontal manufacturer relationships but also explicitly considering alternative vertical strategic behaviors. We do so by deriving and estimating models that allow for two part tariffs and/or resale price maintenance between multiple manufacturers and multiple retailers in the form of non linear vertical contracts.

Using retail scanner data on bottled water produced by manufacturers sold at retail chains in France, we estimate a structural demand and supply model allowing for linear or non linear pricing between manufacturers and retailers. Using price-cost margins recovered from estimates of demand parameters both under linear pricing models and two part tariffs contracts with or without resale price maintenance, and performing non- nested tests among different supply models, we select the best supply model for this industry. We find it to be the case that manufacturers use nonlinear contracts, in the form of two part tariffs with resale price maintenance. We use the estimates of this model to obtain brand-retail level marginal costs. We then perform simulations that restrict the use of these vertical contracts and assess welfare effects under alternative counterfactual supply side scenarios.

Our paper is the first paper to incorporate non-linear pricing into vertical contract analysis. This is done under limited data on wholesale prices and fixed tariffs and it 
brings a new method for the empirical analysis of vertical contracts. Following previous literature we estimate a demand model and derive implied price cost margins at the firm level indirectly (as in Rosse, 1970, Bresnahan 1987, 1989, Berry, 1994, Berry, Levinsohn and Pakes, 1995, Nevo, 1998, 2000, 2001, Ivaldi and Verboven, 2005). A stream of research followed, with papers allowing not only manufacturers but also retailers margins to be recovered considering explicitly the strategic role of retailers: e.g., Goldberg and Verboven (2001), Manuszak (2001), Mortimer (2008), Sudhir (2001), Berto Villas Boas (2007), Villas-Boas and Zhao (2005), Hellerstein (2004), Asker (2004), Ho (2006), and Pakes, Porter, Ho and Ishii (2006). Manuszak (2001) studies the impact of upstream mergers on retail gasoline markets using a structural model allowing downstream prices to be related to upstream mark-ups and wholesale prices chosen by upstream gasoline refineries. Asker (2004) studies exclusive dealing in the beer market. Hellerstein (2004) explains imperfect pass-through again in the beer market. Among the few papers that take into account vertical relationships, Ho (2006) studies the welfare effects of vertical contracting between hospitals and Health Maintenance Organizations in the US. Ho (2008) studies how managed care health insurers restrict their enrollees' choice of hospitals to specific networks using the inequality framework of Pakes, Porter, Ho and Ishii (2006) for identification. In the retail industry, Sudhir (2001) considers strategic interactions between manufacturers and a single retailer on a local market. These recent developments introducing retailers' strategic behavior mostly consider cases where competition between producers and/or retailers remains under linear pricing leading to double marginalization. Berto Villas-Boas (2007) extends Sudhir's framework to multiple retailers and considers the possibility that vertical contracts between manufacturers and retailers make pricing strategies depart from double marginalization by alternatively setting wholesale margins or retail margins to zero.

While the strategic role of retailers has been emphasized as important in the markets (see e.g., Chevalier, Kashyap and Rossi, 2003), and the papers above add a retail horizontal layer in addition to a horizontal manufacturer layer in empirical analyses, no 
paper has yet considered empirically the analysis of the "vertical relationships" between these multiple retailers and manufacturers. Our paper provides a first step towards the analysis of the vertical contracts that may be occurring in the markets, allowing for non linear contracts in the form of two part tariffs. Following Rey and Vergé (2004) and extending it to multiple manufacturers and multiple retailers, two types of nonlinear pricing relationships are considered, one where resale price maintenance is used with two part tariff contracts and one where no resale price maintenance is allowed. Modelling explicitly optimal two part tariff contracts (with or without resale price maintenance) allows total price-cost margins as functions of demand parameters without observing wholesale prices to be estimated. Using non-nested test procedures, it is shown how to test between the different models using exogenous variables that shift the marginal costs of production and distribution.

This methodology is applied to study the market for retailing bottled water in France. This market shows a high degree of concentration both at the manufacturer and retailer levels. It should be noted that this is actually even more concentrated at the manufacturer level. Our empirical evidence suggests that, in the French bottled water market, manufacturers and retailers use nonlinear pricing contracts and in particular two part tariff contracts with resale price maintenance despite the fact that resale price maintenance is forbidden in France. This is an important finding in view of the French regulatory environment for retailing. Actually, during the 1996-2006 years, resale-below-cost was forbidden and defined in such a way that only unit price of invoices were used to define the threshold for retail prices. This law could be easily manipulated by manufacturers who would purposely display high wholesale prices providing a way to implement high retail prices for manufacturers and this circumvent the ban of resale price maintenance. Finally it is also shown how to simulate different counterfactual policies using a structural model as with a de-merger between Perrier and Nestlé, a double marginalization case and a nonlinear relationship between manufacturers and retailers without resale price maintenance. Our results suggest that the merger case of Nestlé and Perrier in 1992 would increase retail 
prices and the remove of the Gallant Act, simulated by the case where no RPM would be used by manufacturers, would decrease retail prices.

The paper proceeds as follows. In section 2, some stylized facts on the market for bottled water in France are given, this being an industry where the questions of vertical relationships and competition of manufacturers and retailers seem worth studying. Section 2 also present available data on this market. Section 3 describes the main methodological contribution on the supply side. It is shown how price-cost margins can be recovered with demand parameters when taking explicitly into account two part tariff contracts and/or resale price maintenance. Section 4 discusses the demand model, its identification and the estimation method proposed as well as the testing method between the different models. Section 5 presents the empirical results for demand, price-cost margins and non-nested tests and section 6 presents some policy simulations. A conclusion with future research directions is in section 7 , and some appendices follow in section 8 .

\section{Bottled Water Market in France and Description of Data}

\subsection{Stylized Facts on the Market for Bottled Water in France}

The French market for bottled water is one of the more dynamic sectors of the French food processing industry: the total production of bottled water increased by $4 \%$ in 2000 , and its revenues by $8 \%$. Some $85 \%$ of French consumers drink bottled water, and over two thirds of French bottled water drinkers drink it more than once a day, a proportion exceeded only in Germany. The French bottled water sector is highly concentrated, the three main manufacturers (Nestlé, Danone, and Castel) sharing $90 \%$ of total production for the sector. Moreover, given the scarcity of natural springs, entry onto the mineral or spring water market is difficult. Compte, Jenny and Rey (2002) comment on the Nestlé/Perrier Merger case that took place in 1992 in Europe and point out that in addition to the high concentration of the sector, these capacity constraints are a factor for collusion. The sector can be divided in two major segments: mineral water and spring water. Natural mineral water benefits from some properties favorable to health, which are officially recognized. 
Composition must be guaranteed as well as the consistency of a set of qualitative criteria: mineral content, appearance, and taste. Mineral water can be marketed if it receives a certification from the French Ministry of Health. Exploitation of a spring water source requires only a license provided by the authorities (Prefectures) and approved from the local health administration. Moreover, composition of the water is not required to be constant. Differences between the quality requirements involved in certification of the two kinds of bottled water may explain part of the substantial difference that exists between the shelf prices of national mineral water brands and local spring water brands. Moreover, national mineral water brands are highly advertised. Bottled water products mainly use two kinds of differentiation. The first kind of differentiation stems from the mineral composition, that is the mineral salts content, and the second from the brand image conveyed through advertising. At present, thanks to data at the aggregate level (Agreste, 1999, 2000, 2002) on food industries and the bottled water industry, it can be seen (see the following Table 1) that this industry uses much more advertising than other food industries. Friberg and Ganslandt (2003) report an advertising to revenue ratio for the same industry in Sweden of $6.8 \%$ over the $1998-2001$ period. By comparison, the highest advertising to revenue ratio in the US food processing industry corresponds to the ready-to-eat breakfast cereals industry and stands at $10.8 \%$. These figures may be interpreted as showing the significance of horizontal differentiation of products for bottled water.

\begin{tabular}{ccccc}
\hline \hline Year & \multicolumn{2}{c}{ Bottled Water } & \multicolumn{2}{c}{ All Food Industries } \\
& Price Cost Margin & Advertising/Revenue & Price Cost Margin & Advertising/Revenue \\
\hline 1998 & $17.38 \%$ & $12.09 \%$ & $6.32 \%$ & $5.57 \%$ \\
1999 & $16.70 \%$ & $14.91 \%$ & $6.29 \%$ & $6.81 \%$ \\
2000 & $13.61 \%$ & $15.89 \%$ & $3.40 \%$ & $8.76 \%$ \\
\hline \hline
\end{tabular}

Table 1: Aggregate Estimates of Margins and Advertising to Sales Ratios.

These aggregate data also allow us to obtain accounting price-cost margins ${ }^{1}$ defined as value added ${ }^{2}(V A)$ minus payroll $(P R)$ and advertising expenses $(A D)$ divided by the

\footnotetext{
${ }^{1}$ The underlying assumptions in the definition of these price-cost margins are that the marginal cost is constant and is equal to the average variable cost (see Liebowitz, 1982).

${ }^{2}$ Value added is defined as the value of shipments plus services rendered minus cost of materials, supplies and containers, fuel, and purchased electrical energy.
} 
value of shipments $(T R)$. As stressed by Nevo (2001), these accounting estimates can be considered as an upper bound to the true price-cost margins.

Recently, degradation of the tap water distribution network has led to an increase in bottled water consumption. This increase benefited the cheapest bottled water, that is, local spring water. For instance, the total volume of local spring water sold in 2000 approached the total volume of mineral water sold the same year. Households buy bottled water mostly in supermarkets, representing $80 \%$ of the total sales of bottled water. Moreover, on average, these sales represent $1.7 \%$ of the total turnover of supermarkets, the bottled water shelf being one of the most productive. French bottled water manufacturers thus mainly deal their brands through retail chains. These chains are also highly concentrated, the market share of the top five accounting for $80.7 \%$ of total food product sales. Moreover, over the last few years, as in other processed food products, these chains have developed their own private labels ${ }^{3}$ to attract consumers. The increase in the number of such private labels tends to be accompanied by a reduction in the market share of the main national brands.

We thus face a relatively concentrated market where competition issues and evaluation of markups are very important. In such market, it seems important to take into account the possibility that nonlinear pricing may be used between manufacturers and retailers. As a rule, two part tariffs are relatively simple contracts that may allow manufacturers to benefit from their bargaining position in selling national brands.

\subsection{Data and Variables}

Our data were collected by the company TNS-WorldPanel and is representative of households' consumption in France. It is a home-scan data set by nearly 11,000 French households for the years 1998, 1999 and 2000, containing information on their purchases of all food products. The data on all food purchases are obtained through home scan technique and provide a description of the main characteristics of the goods and records the quantity,

\footnotetext{
${ }^{3}$ The Private Label (aldo named Store Brand or Own Brand in the UK) products encompass all merchandis sold under a retailer's brand. That brand can be the retailer's own name or a name created exclusively by that retailer. Retailers define characteristics of these brands and owns and controls them.
} 
the price, the date and the store for all purchases over the whole period, and in particular on all bottled water purchased by these French households during the three years of study. We consider purchases in the seven most important retailers that represent $70.7 \%$ of the total purchases in the sample. The most important brands are taken into account, that is, five national brands of mineral water, one national brand of spring water, one retailer private label brand of mineral water and one retailer private label spring water. Purchases of these eight brands represent $71.3 \%$ of the purchases for the seven retailers in our sample. As will be shown in the demand estimation, robustness analysis is conducted in order to assess whether this selection of the most important brands introduces significant bias in the inference or not. The national brands are produced by three different manufacturers: Danone, Nestlé and Castel. This survey has the advantage of allowing market shares that are representative of the national French market to be computed thanks to a weighting procedure of the available household panel. Market shares are then defined by a weighted sum of the purchases of each brand during each month divided by the total market size of the respective month. The market share of the outside good is defined as the difference between the total size of the market and the shares of the inside goods. Drinking water is assumed to be consumed by all households of the panel. Thus, the outside good concerns tap water used only for drinking purposes as well as still bottled water sold by retail stores not considered in the analysis and still water from small manufacturers sold in the seven retail stores studied. Considering that an individual has a mean drinking water consumption of 1.76 liters per day or 53 liters per month (Gofti-Laroche et al., 2001), the total size of the market can be computed by multiplying the monthly mean consumption by the total number of individuals in our panel each year.

Eight brands sold in seven distributors were considered, which gives more than 50 differentiated products on this national market. A product is defined by its brand and the retailer chain where it is sold. The number of products in our study thus varies between 51 and 54 over the 3 years considered. Considering the monthly (periods of 4 weeks are used) market shares of all of these differentiated products, we get a total of 
2041 observations in our sample. Note that when computing the aggregate market share, multiple choices and multiple purchases of households within each four-week period are implicitly included, which is equivalent to considering these multiple choices as coming from different purchase occasions in the random utility demand model considered. Then, for each of these products, an average price can also be computed for each month (in euros per liter). These data present both advantage and drawbacks. The advantage is that reliable nationally representative data can be used rather than data from just a few stores. The sample being quite large, it allows to compute monthly market shares and monthly prices without too much missing information. In fact, as all brands are purchased by some households at every retailer chain every month, the prices of all products are consistently observed and it can be considered that all prices are observed in the choice set of consumers for each period if prices were constant within that period. In practice, the prices computed are average prices of purchase of the same brand in the same retailer within the 4 weeks period and are based on average on 140 purchases per period. However, prices do vary within the four-week period implying a possible aggregation bias. Table 2 below shows the variance decomposition of these purchase prices showing that $38.5 \%$ of the variance of these prices is due to the within month variation of prices of brands in the same retailer. This is of course relatively large. Thus, some robustness analysis with respect to this potential variability of prices within periods is necessary. The observed variance of prices within each month will be used to assess the robustness of estimation of our demand model.

\begin{tabular}{lcccc}
\hline \hline $\begin{array}{l}\text { Analysis of Variance } \\
\text { of price }\end{array}$ & $\begin{array}{c}\text { Partial Sum } \\
\text { of Squares }\end{array}$ & $\begin{array}{c}\text { Degrees } \\
\text { of freedom }\end{array}$ & F & P value \\
\hline Month & 131.77 & 38 & 11.04 & 0.00 \\
Brand & 31789.76 & 7 & 14452 & 0.00 \\
Retailer & 213.71 & 6 & 113.35 & 0.00 \\
Brand*Retailer & 607.8 & 40 & 48.36 & 0.00 \\
Brand*Month & 1482.57 & 266 & 17.74 & 0.00 \\
Retailer*Month & 200.25 & 228 & 2.79 & 0.00 \\
Brand*Retailer*Month & 1473.55 & 1455 & 3.22 & 0.00 \\
\hline $\mathrm{R}^{2}$ & 0.614 & & & \\
\hline \hline
\end{tabular}

Table 2: Analysis of variance of the price of each purchase

Table 2 also shows that the brand, retailer and time variation are all statistically 
significant in the analysis of variance of prices of household purchases. It appears that the most important variation is the one across brands even if the time variation is important and the retailer one too. The price obtained averaging by brand, retailer and month still varies substantially across retailers and across periods for a given brand as shown by the significant interaction effects of the retailer and month variables in the decomposition of the variance of price in Table 3 .

Table 3 presents some first descriptive statistics on the main variables used. We can see that mineral water prices are twice larger than spring water prices and that we have the same remark for market shares. The outside good is quite large since it represents $71 \%$ of the total size of the market.

\begin{tabular}{lcccccc}
\hline \hline Variable & Mean & Median & Std. dev. & Min. & Max & Nb. Obs. \\
\hline \hline Per Product Market share (all inside goods) & 0.005 & 0.003 & 0.006 & $4.10^{-6}$ & 0.048 & 2041 \\
Per Product Market share: Mineral Water & 0.004 & 0.003 & 0.003 & $10^{-6}$ & 0.048 & 1496 \\
Per Product Market share: Spring Water & 0.010 & 0.007 & 0.010 & $10^{-5}$ & 0.024 & 545 \\
Price in E/liter & 0.298 & 0.323 & 0.099 & 0.096 & 0.823 & 2041 \\
Price in €/liter: Mineral Water & 0.346 & 0.343 & 0.060 & 0.128 & 0.823 & 1496 \\
Price in $€ /$ liter: Spring Water & 0.169 & 0.157 & 0.059 & 0.096 & 0.276 & 545 \\
Mineral water dummy (0/1) & 0.73 & 1 & 0.44 & 0 & 1 & 2041 \\
Market Share of the Outside Good & 0.71 & 0.71 & 0.04 & 0.59 & 0.78 & 39 \\
\hline \hline
\end{tabular}

Table 3: Summary Statistics

Data from the French National Institute of Statistics and Economic Studies (INSEE) were also used on the plastic price, on a wage salary index for France, on oil and diesel fuel prices and on an index for packaging material cost. Over the time period considered (19982000), the wage salary index always rose while the plastic price index first declined during 1998 and the beginning of 1999 before rising again and reaching the 1998 level at the end of 2000. Concerning the diesel fuel price index, this shows quite significant volatility with a first general decline during 1998 before a sharp increase until a new decline at the end of 2000. Also, the packaging material cost index shows substantial variations with sharp growth in 1998, a decline at the beginning of 1999 and again an appreciable growth until the end of 2000.

The next section studies different alternative models of strategic relationships between 
multiple manufacturers and multiple retailers worthy of consideration.

\section{Competition and Vertical Relationships Between Manu- facturers and Retailers}

Before presenting our demand model, modelling of competition and vertical relationships between manufacturers and retailers is presented. Given the structure of the bottled water industry and the retail industry in France, several oligopoly models with different vertical relationships are considered. More precisely, using a particular game form (as in Rey and Vergé (2004) and Berto Villas-Boas (2007)) that will be detailed below, it is shown how each supply model can be solved to obtain an expression for both the retailer's and manufacturer's price-cost margins as a function of demand side parameters and the structure of the industry. Then using estimates of a differentiated products demand model, these price-cost margins can be estimated empirically and it will be shown how these competing scenarios can be tested in the next section. A similar methodology has already been used for double marginalization scenarios considered below by Sudhir (2001) or Brenkers and Verboven (2006) or Berto Villas-Boas (2007) but none of the papers in this literature have addressed the particular case of competition in two part tariffs using the recent theoretical insights of Rey and Vergé (2004).

Notations will be as follows. There are $J$ differentiated products defined by the brandretailer couple corresponding to $J^{\prime}$ national brands and $J-J^{\prime}$ private labels. It is assumed there are $R$ retailers competing in the retail market and $F$ manufacturers competing in the wholesale market. $S_{r}$ denotes the set of products sold by retailer $r$ and $G_{f}$ the set of products produced by firm $f$. In the following we successively present the different oligopoly models to be studied. Note that the set of products and their ownership will be considered as being exogenous to our model, such that all ownership matrices defined are exogenous. A next step in this research would be to endogenize the set of products, brand ownership by manufacturers and the retailers choice of brand variety. 


\subsection{Linear Pricing and Double Marginalization}

In this model, the manufacturers set their prices first, and retailers follow, setting the retail prices given the wholesale prices (we will use the term "Stackelberg" for this assumption). For private labels, prices are chosen by the retailer himself who acts as though owning both manufacturing and retailing. Competition is considered $\grave{a}$ la Nash-Bertrand at the horizontal level. This vertical model is solved by backward induction considering the retailer's problem first. The profit $\Pi^{r}$ of retailer $r$ in a given period (the time subscript $t$ is dropped for ease of presentation) is given by

$$
\Pi^{r}=\sum_{j \in S_{r}}\left(p_{j}-w_{j}-c_{j}\right) s_{j}(p) M
$$

where $p_{j}$ is the retail price of product $j$ sold by retailer $r, w_{j}$ is the wholesale price paid by retailer $r$ for product $j, c_{j}$ is the retailer's (constant) marginal cost of distribution for product $j, s_{j}(p)$ is the market share of product $j, p$ is the vector of all product's retail prices and $M$ is the size of the market (including the outside good). Assuming that a pure-strategy Bertrand-Nash equilibrium in prices exists and that equilibrium prices are strictly positive, the price of any product $j$ sold by retailer $r$ must satisfy the first-order conditions

$$
s_{j}+\sum_{k \in S_{r}}\left(p_{k}-w_{k}-c_{k}\right) \frac{\partial s_{k}}{\partial p_{j}}=0, \quad \text { for all } j \in S_{r} .
$$

Note that for private labels, this price-cost margin is in fact the total price cost margin $p_{k}-\mu_{k}-c_{k}$ which amounts to replacing the wholesale price $w_{k}$ by the marginal cost of production $\mu_{k}$ in this formula.

Concerning the manufacturers' behavior, it is also assumed that each of them maximizes profit choosing the wholesale prices $w_{j}$ of the product $j$ he sells and given the retailers' response (1). The profit of manufacturer $f$ is given by

$$
\Pi^{f}=\sum_{j \in G_{f}}\left(w_{j}-\mu_{j}\right) s_{j}(p(w)) M
$$

where $\mu_{j}$ is the manufacturer's (constant) marginal cost of production of product $j$. Assuming the existence of a pure-strategy Bertrand-Nash equilibrium in wholesale prices 
between manufacturers, the first order conditions are

$$
s_{j}+\sum_{k \in G_{f}} \sum_{l=1, . ., J}\left(w_{k}-\mu_{k}\right) \frac{\partial s_{k}}{\partial p_{l}} \frac{\partial p_{l}}{\partial w_{j}}=0, \quad \text { for all } j \in G_{f} .
$$

The derivatives of retail prices with respect to wholesale prices depend on the strategic interactions between manufacturers and retailers and can be deduced from the total differentiation of the retailer's first order conditions (1) with respect to wholesale price, i.e. for $j \in S_{r}$ and $k=1, . ., J^{\prime}$

$$
\sum_{l=1, . ., J} \frac{\partial s_{j}(p)}{\partial p_{l}} \frac{\partial p_{l}}{\partial w_{k}}-1_{\left\{k \in S_{r}\right\}} \frac{\partial s_{k}(p)}{\partial p_{j}}+\sum_{l \in S_{r}} \frac{\partial s_{l}(p)}{\partial p_{j}} \frac{\partial p_{l}}{\partial w_{k}}+\sum_{l \in S_{r}}\left(p_{l}-w_{l}-c_{l}\right) \sum_{s=1, . ., J} \frac{\partial^{2} s_{l}(p)}{\partial p_{j} \partial p_{s}} \frac{\partial p_{s}}{\partial w_{k}}=0 .
$$

This expression derives from the assumption that manufacturers play first in the vertical relationships with retailers. In the case where we assume that retailers and manufacturers set their prices simultaneously, we can infer like Sudhir (2001) that only the direct effect of wholesale price on retail price matter through the change in the marginal cost of products for the retailer. Thus, the retailer's cost of input is accounted for in the retailer's choice of margin. Both the manufacturer and retailer take the retail price as given and play a Nash game in margins.

For retailers and for manufacturers, we thus obtain a system of equations (1) and another system of equations (2) that can be solved (see appendix 8.2) to obtain the expression of retail and wholesale margins of all products, respectively, as a function of demand parameters and of the structure of the industry.

\subsection{Two-Part Tariffs}

The case is now considered where manufacturers and retailers sign two-part tariff contracts in a particular game form. Rey and Vergé (2004) prove the existence of and characterize equilibria under some conditions on elasticities of demand and the shape of profit function to a (double) common agency game in a two manufacturer - two retailer version ${ }^{4}$. It

\footnotetext{
${ }^{4}$ These technical assumptions require that direct price effects dominate in demand elasticities such that if all prices increase, demand decreases. The empirical estimation of demand will confirm that this is the case for bottled water in France. Moreover, the monopoly profit function of the industry has to be single peaked as well as manufacturers revenue functions of the wholesale price vector.
} 
is assumed that manufacturers simultaneously propose take-it or leave-it offers of twopart tariff contracts to each retailer. These contracts are public information and involve specifying franchise fees and wholesale prices but also retail prices in the case where manufacturers can use resale price maintenance. If one offer is rejected, then all contracts are refused ${ }^{5}$. If all offers are accepted, the retailers simultaneously set their retail prices and contracts are implemented.

The fact that manufacturers make offers and that once an offer is rejected no contract is signed puts retailers at their participation constraint, i.e. their profit should be equal to the minimum profit that the retailer can obtain if all contracts on this market are rejected. This outside option of the retailers is assumed to be given exogenously. Endogenizing the outside option is left for future research and is outside the scope of the present paper. It has to be noted that this theoretical model implies that the true profits of manufacturers and retailers are not identified since the reservation utilities can shift rents between parties without changing equilibria. Another remark consists in the fact that allowing retailers to make offers first would shift rents from the manufacturer to the retailer but the set of price equilibria would be defined by the same sets of first order conditions. Moreover assuming that the offers of manufacturers are public is a convenient modelling hypothesis that can be justified in France by the non-discrimination laws coming from the 1986 edict on free price setting ${ }^{6}$ which prevent in principle to offer different prices to purchasers who provide comparable services.

In the case of these two part tariff contracts, the profit function of retailer $r$ is:

$$
\Pi^{r}=\sum_{j \in S_{r}}\left[M\left(p_{j}-w_{j}-c_{j}\right) s_{j}(p)-F_{j}\right]
$$

where $F_{j}$ is the franchise fee paid by the retailer for selling product $j$.

Manufacturers set their wholesale prices $w_{k}$ and the franchise fees $F_{k}$ in order to

\footnotetext{
${ }^{5}$ The characterization of equilibria in the opposite case is more difficult (Rey and Vergé, 2004). However, this assumption means that all manufacturers trading with all retailers should be observed, which is the case for bottled water in France.

${ }^{6}$ From 1986, restrictive pricing practices such as resale price maintenance, below-cost prices or discriminatory pricing were prohibited. In 1996, the Galland law, strengthened penalties against resale at loss (below-cost prices) by defining clearly the threshold as the net invoice unit price set by suppliers. Backroom margins which gather diverse fees such as slotting allowances, deferred price reductions or payment for commercial services obtained by retailers could not be included in the resale-below-cost threshold.
} 
maximize profits equal to

$$
\Pi^{f}=\sum_{k \in G_{f}}\left[M\left(w_{k}-\mu_{k}\right) s_{k}(p)+F_{k}\right]
$$

for firm $f$, subject to retailers' participation constraints $\Pi^{r} \geq \bar{\Pi}^{r}$, for all $r=1, . ., R$, where $\bar{\Pi}^{r}$ is the outside option of retailer $r$, supposed exogenous.

As shown in Rey and Vergé (2004), participation constraints are binding since otherwise manufacturers could increase the fixed fees $F_{k}$ given those of other manufacturers. The expressions for the franchise fee $F_{k}$ of the binding participation constraint can be substituted into the manufacturer's profit (5) to obtain the following profit for firm $f$ (see details in appendix 8.1 where reservation utilities $\bar{\Pi}^{r}$ are simply a constant to be added and that can be normalized to zero):

$$
\Pi^{f}=\sum_{k \in G_{f}}\left(p_{k}-\mu_{k}-c_{k}\right) s_{k}(p)+\sum_{k \notin G_{f}}\left(p_{k}-w_{k}-c_{k}\right) s_{k}(p)-\sum_{j \notin G_{f}} F_{j}
$$

This shows that each manufacturer fully internalizes the entire margins on his products but internalizes only the retail margins on rivals' products. Note that the additional term

$\sum_{j \notin G_{f}} F_{j}$ is constant for the manufacturer $f$ and thus maximizing the profits of $f$ is equivalent to maximizing the sum (6) without this term. Furthermore, maximization of this objective function depends on whether resale price maintenance is used or not by manufacturers.

Note that even if we assume publicly observable contracts and if retail price maintenance is illegal in France, it is nevertheless interesting to consider such an equilibrium since antitrust authorities may fail to enforce these regulatory constraints, or because it could be obtained by other means through more complicated nonlinear contracts (with more than two parts) without explicit RPM. We then consider two cases for this two part tariffs contracts: one where resale price maintenance is allowed and one where resale price maintenance is forbidden.

\subsubsection{Two part tariffs with resale price maintenance}

Consider the case where manufacturers can use resale price maintenance. Rey and Vergé (2004) show that it is always a dominant strategy for manufacturers to set retail prices 
in their contracting relationship with retailers, which is intuitive since by choosing retail prices and wholesale prices the manufacturer can at least replicate the equilibrium obtained by letting retailers fix their prices given wholesale prices and sometimes do better.

Since manufacturers can capture retail profits through franchise fees and also set retail prices, wholesale prices have no direct effect on profit. The profit expression (6) shows that using RPM, the manufacturer's choice of wholesale prices for its own products does not affect its profit but that the wholesale prices of other products chosen by other manufacturers affect its own profit. This is why wholesale prices have a strategic role for each manufacturer because they do not affect their own profit but affect the ones of other manufacturers and thus affect their strategic choices of retail prices (through the fact that they affect market shares of all products).

Manufacturers have more control variables than needed and Rey and Vergé (2004) showed that this generates multiple equilibria (a continuum), with one for each wholesale prices vector that influence the strategic behavior of competitors. Thus, for each wholesale price vector $w^{*}$, there exists a symmetric subgame perfect equilibrium ${ }^{7}$ in which retailers earn zero profit and manufacturers set retail prices to $p^{*}\left(w^{*}\right)$, where $p^{*}\left(w^{*}\right)$ is a decreasing function of $w^{*}$ equal to the monopoly price when the wholesale prices are equal to the marginal cost of production.

Moreover, equation (6) also shows that, if there was not private label products that will treat specially later, when wholesale prices are equal to the marginal cost of production, then the two part tariffs contracts allow to maximize the full profits of the integrated industry.

For a given equilibrium $p^{*}\left(w^{*}\right)$, the program of manufacturer $f$ is now

$$
\max _{\left\{p_{k}\right\} \in G_{f}} \sum_{k \in G_{f}}\left(p_{k}-\mu_{k}-c_{k}\right) s_{k}(p)+\sum_{k \notin G_{f}}\left(p_{k}^{*}-w_{k}^{*}-c_{k}\right) s_{k}(p)
$$

Thus, we can write the first order conditions for this program as

$$
\sum_{k \in G_{f}}\left(p_{k}-\mu_{k}-c_{k}\right) \frac{\partial s_{k}(p)}{\partial p_{j}}+s_{j}(p)+\sum_{k \notin G_{f}}\left(p_{k}^{*}-w_{k}^{*}-c_{k}\right) \frac{\partial s_{k}(p)}{\partial p_{j}}=0 \quad \text { for all } j \in G_{f}
$$

\footnotetext{
${ }^{7}$ Rey and Vergé (2004) prove the existence of symmetric equilibria with two symmetric manufacturers and two symmetric retailers.
} 
Then, depending on the wholesale prices, assuming that the first order conditions are sufficient (Rey and Vergé (2004) give examples of conditions on profit functions that will insure that it is the case), several equilibria can be considered.

First, we consider the case where wholesale prices are equal to the marginal cost of production $\left(w_{k}^{*}=\mu_{k}\right)$. In this case, retailers act as residual claimants and manufacturers capture the full monopoly rents through fixed fees. The first order conditions (7) can be expressed

$$
\sum_{k \in G_{f}}\left(p_{k}-\mu_{k}-c_{k}\right) \frac{\partial s_{k}(p)}{\partial p_{j}}+s_{j}(p)+\sum_{k \notin G_{f}}\left(p_{k}^{*}-\mu_{k}-c_{k}\right) \frac{\partial s_{k}(p)}{\partial p_{j}}=0 \quad \text { for all } j \in G_{f}
$$

i.e.

$$
\sum_{k=1}^{J}\left(p_{k}-\mu_{k}-c_{k}\right) \frac{\partial s_{k}(p)}{\partial p_{j}}+s_{j}(p)=0 \quad \text { for all } j \in G_{f}
$$

In the case of private label products, retailers choose retail prices and bear the marginal cost of production and distribution, maximizing:

$$
\max _{\left\{p_{j}\right\}_{j \in \tilde{S}_{r}}} \sum_{k \in S_{r}}\left(p_{k}-\mu_{k}-c_{k}\right) s_{k}(p)
$$

where $\widetilde{S}_{r}$ is the set of private label products of retailer $r$. Thus, for private label products, additional equations are obtained from the first order conditions of the profit maximization of retailers that both produce and retail these products. The first order conditions give

$$
\sum_{k \in S_{r}}\left(p_{k}-\mu_{k}-c_{k}\right) \frac{\partial s_{k}(p)}{\partial p_{j}}+s_{j}(p)=0 \quad \text { for all } j \in \widetilde{S}_{r}
$$

We thus obtain a system of equations with (8) and (9) that can be solved (see appendix 8.2), to obtain the expression for the total price-cost margin of all products as a function of demand parameters and of the structure of the industry.

Note that in the absence of private label products, the expression obtained and that solves this system simplifies to the case where the total profits of the integrated industry. This shows that two part tariff contracts with $R P M$ allow manufacturers to maximize the full profits of the integrated industry if retailers have no private label products. 
Second, we consider the case where wholesale prices are such that the retailer's price cost margins are zero $\left(p_{k}^{*}\left(w_{k}^{*}\right)-w_{k}^{*}-c_{k}=0\right)$. This case is considered by Berto VillasBoas (2007) and implies that retail prices are chosen to maximize profits corresponding to the downstream vertically integrated structure for each of the $J$ products. The retailers add only retail costs to the wholesale prices. In equilibrium, pricing decisions are thus implemented by the manufacturers and the share of total profits between retailers and manufacturers is then unidentified and will depend on the reservation profits $\bar{\Pi}^{r}$ of each retailer. Then (7) becomes

$$
\sum_{k \in G_{f}}\left(p_{k}-\mu_{k}-c_{k}\right) \frac{\partial s_{k}(p)}{\partial p_{j}}+s_{j}(p)+\sum_{k \in\left\{J^{\prime}, . ., J\right\}}\left(p_{k}-\mu_{k}-c_{k}\right) \frac{\partial s_{k}(p)}{\partial p_{j}}=0 \quad \text { for all } j \in G_{f}
$$

because products in $\left\{J^{\prime}, . ., J\right\}$ are private labels which are also implicitly included in (7). In this case, profit maximizing strategic pricing of private labels by retailers is also taken into account by manufacturers when they choose fixed fees and retail prices for their own products in the contract. The prices of private labels chosen by retailers are such that they maximize their profit on these private labels.

Also in this case, we then obtain expression for the total price cost margins of all national brands given the retail price cost margins of private labels as a function of demand parameters and of the structure of the industry (see Appendix 8.2).

\subsubsection{Two part tariffs without resale price maintenance}

Consider now the case where resale price maintenance cannot be used by manufacturers. Since they cannot choose retail prices, they just set wholesale prices in the following maximization program

$$
\max _{\left\{w_{k}\right\} \in G_{f}} \sum_{k \in G_{f}}\left(p_{k}-\mu_{k}-c_{k}\right) s_{k}(p)+\sum_{k \notin G_{f}}\left(p_{k}-w_{k}-c_{k}\right) s_{k}(p) .
$$

Then the first order conditions are for all $i \in G_{f}$

$\sum_{k} \frac{\partial p_{k}}{\partial w_{i}} s_{k}(p)+\sum_{k \in G_{f}}\left[\left(p_{k}-\mu_{k}-c_{k}\right) \sum_{j} \frac{\partial s_{k}}{\partial p_{j}} \frac{\partial p_{j}}{\partial w_{i}}\right]+\sum_{k \notin G_{f}}\left[\left(p_{k}-w_{k}-c_{k}\right) \sum_{j} \frac{\partial s_{k}}{\partial p_{j}} \frac{\partial p_{j}}{\partial w_{i}}\right]=0$

that allows for an estimate of the price-cost margins with demand parameters using (1) to replace $\left(p_{k}-w_{k}-c_{k}\right)$ and (3) for all the $\frac{\partial p_{j}}{\partial w_{i}}$. 
We are thus able to obtain several expressions for price-cost margins at the manufacturing or retail levels under the different models considered as a function of demand parameters and of the structure of the industry (see detailed expressions in appendix 8.2).

\section{Differentiated Product Demand}

\subsection{The Random Coefficients Logit Model}

We use a random-coefficients logit model for the demand estimated using the method of Berry, Levinsohn, and Pakes (1995). Contrary to the standard logit model, the randomcoefficients logit model imposes very few restrictions on own and cross-price elasticities (McFadden and Train, 2001). This flexibility makes it the most appropriate model to obtain consistent estimates of the demand parameters required for computation of pricecost margins.

The basic specification of the indirect utility function giving rise to demand is given by

$$
V_{i j t}=\beta_{j}+\gamma_{t}-\alpha_{i} p_{j t}+\xi_{j t}+\varepsilon_{i j t}
$$

where $V_{i j t}$ denotes the indirect latent utility of consumer $i$ from buying product $j$ during month $t, \beta_{j}$ represents product fixed effects capturing time invariant product characteristics, $\gamma_{t}$ are time dummies capturing monthly unobserved determinants of demand (like the weather), $p_{j t}$ is the price of product $j$ during month $t, \xi_{j t}$ identifies the mean across consumers of unobserved (by the econometrician) changes in product characteristics, and $\varepsilon_{i j t}$ represents separable additive random shocks. The random coefficient $\alpha_{i}$ represents the unknown marginal disutility of price for consumer $i$. This coefficient is allowed to vary across consumers according to

$$
\alpha_{i}=\alpha+\sigma v_{i}
$$

where $v_{i}$ summarizes all the unobserved consumer characteristics, and $\sigma$ is a coefficient that characterizes how consumer marginal disutilities of price vary with respect to average disutility $\alpha$ according to these unobserved characteristics. Indirect utility can be redefined in terms of the mean utility $\delta_{j t}=\beta_{j}+\gamma_{t}-\alpha p_{j t}+\xi_{j t}$ and deviations from the mean utility 
$\mu_{i j t}=-\sigma v_{i} p_{j t}$, i.e.

$$
V_{i j t}=\delta_{j t}+\mu_{i j t}+\varepsilon_{i j t}
$$

The model is completed by the inclusion of an outside good, denoted good zero, allowing for the possibility of consumer $i$ not buying one of the $J_{t}$ marketed products. The price of this good is assumed to be set independently of the prices observed in the sample. The mean utility of the outside good is normalized to be zero and constant over time. The indirect utility of choosing the outside good is $U_{i 0 t}=\varepsilon_{i 0 t}$.

Idiosyncratic tastes $\varepsilon_{i j t}$ are assumed to be independently and identically distributed according to Gumbel (extreme value type I) distribution. $v_{i}$ is assumed to be normally distributed. Under these assumptions, the market share of product $j$ for month $t$ is given by

$$
s_{j t}=\int_{A_{j t}}\left(\frac{\exp \left(\delta_{j t}+\mu_{i j t}\right)}{1+\sum_{k=1}^{J_{t}} \exp \left(\delta_{k t}+\mu_{i k t}\right)}\right) \phi\left(v_{i}\right) d v_{i}
$$

where $A_{j t}$ denotes the set of consumers traits that induce the purchase of product $j$ during month $t$. Moreover, denoting $s_{i j t} \equiv \exp \left(\delta_{j t}+\mu_{i j t}\right) /\left(1+\sum_{k=1}^{J_{t}} \exp \left(\delta_{k t}+\mu_{i k t}\right)\right)$, the own and cross-price elasticities of the market share $s_{j t}$ defined by equation (10) are

$$
\eta_{j k t} \equiv \frac{\partial s_{j t}}{\partial p_{k t}} \frac{p_{k t}}{s_{j t}}=\left\{\begin{array}{cl}
-\frac{p_{j t}}{s_{j t}} \int \alpha_{i} s_{i j t}\left(1-s_{i j t}\right) \phi\left(v_{i}\right) d v_{i} & \text { if } j=k \\
\frac{p_{k t}}{s_{j t}} \int \alpha_{i} s_{i j t} s_{i k t} \phi\left(v_{i}\right) d v_{i} & \text { otherwise. }
\end{array}\right.
$$

The random-coefficients logit model generates a flexible pattern of substitutions between products driven by the different consumer price disutilities $\alpha_{i}$. Indeed, each consumer will have a different price disutility, which will be averaged to a mean price sensitivity using the consumer specific probabilities of purchase $s_{i j t}$ as weights. Therefore, crossprice elasticities will not be constrained by the assumptions of homogeneity of marginal price disutility across consumers and by the functional form of probabilities as in the standard logit model.

Coming to the estimation of this model, Berry, Levinsohn and Pakes (1995) show how to estimate the demand parameters using data on market shares per product and period to estimate $s_{j t}$, on prices $p_{j t}$ and characteristics of goods. The GMM estimator is formed $^{8}$ using instrumental variables that need to be orthogonal to unobserved demand

\footnotetext{
${ }^{8}$ Nevo (2001) Matlab code was used to perform these estimations.
} 
determinants $\xi_{j t}$ that appear in the demand, under the assumption that there is no serial correlation of these unobservable shocks (after estimation, we have checked this assumption which appears satisfied). As presented in the section 2, we use a household home scan data to obtain aggregate market shares per product and period $s_{j t}$ as the total quantity purchased of product $j$ during period $t$ divided by the size of the market, and we use the purchase data to obtain an average price $p_{j t}$. The characteristics of the good such as the brand name, the retailer name, the minerality of water are all contained in these data whose purchase information is at the bar code level.

As we also need instrumental variables that are collected from outside sources. Actually, we also use the price of inputs of the bottling process as instruments. In fact, input prices should not be correlated with consumer demand shocks. The instruments used are the wage salary index for France and the diesel fuel and packaging material price indices. Indeed, labor, diesel fuel and packaging materials are three significant production factors in the processing and packaging of bottled water. As emphasized by Hellerstein (2004), input prices such as wages are unlikely to have any relationship to the types of promotional activity that will stimulate perceived changes in the characteristics of the products considered. These monthly figures come the French National Institute for Statistics and Economic Studies. These indices are interacted with dummy variables on the characteristics of each product as with the minerality of water. The underlying intuition is to allow each input to enter the production function of each product differently. In fact, it is likely that labor cost is not the same for the production of mineral and spring water (there are not the same requirements in terms of monitoring the quality of water at the production stage and thus it is likely that mineral water requires more monitoring and thus costs more in labor) but it is also known in this industry that the quality of plastic used for mineral or spring water is usually not the same and this is also likely to affect their bottling and packaging costs. Also, the relatively significant variations of all these price indices during the period of study suggests a potentially good identification of our cost equations. 


\subsection{Testing Between Alternative Models}

We now present how to test between alternative models once we have estimated the demand model and obtained the different price-cost margin estimates in accordance with the expressions obtained in the section 3. The estimation procedure consisting in estimating the demand model separately from the supply model is simple since it dispenses with the need to reestimate the demand model for each supply model considered (Appendix 8.4 discusses the conditions of identification of the model in a one step procedure).

Then, for each supply model, we have a price cost margin and thus an estimate of the total marginal cost (sum of the marginal cost of distribution and of production). The idea of the following test which allows to infer which supply model is preferred consists in testing each model against each other using some identifying restrictions imposed on the cost estimates. Observing some additional variables supposed to affect marginal costs can help infer which model is the best by looking at which estimated marginal costs are the most correlated to such variables. The statistical method used is described below. Note that testing each model against each other does not guarantee that the inference will lead to a unique preferred model since there is no guarantee of transitivity of the tests. It remains an empirical question.

Considering model $h$, we denote $\gamma_{j t}^{h}$ the retailer price cost margin for product $j$ at time $t$ and $\Gamma_{j t}^{h}$ the manufacturer price cost margin under this model. Using $C_{j t}^{h}=\mu_{j t}^{h}+c_{j t}^{h}$ for the sum of the marginal cost of production and distribution, we know that

$$
C_{j t}^{h}=p_{j t}-\Gamma_{j t}^{h}-\gamma_{j t}^{h}
$$

Assume now the following specification for these marginal costs

$$
C_{j t}^{h}=p_{j t}-\Gamma_{j t}^{h}-\gamma_{j t}^{h}=\left[\exp \left(\omega_{j}^{h}+W_{j t}^{\prime} \lambda_{h}\right)\right] \eta_{j t}^{h}
$$

where $\omega_{j}^{h}$ is an unknown product specific parameter, $W_{j t}$ are observable random shocks to the marginal cost of product $j$ at time $t$ and $\eta_{j t}^{h}$ is an unobservable random shock to the cost. Taking logarithms, the following is obtained

$$
\ln C_{j t}^{h}=\omega_{j}^{h}+W_{j t}^{\prime} \lambda_{h}+\ln \eta_{j t}^{h}
$$


Assuming that $E\left(\ln \eta_{j t}^{h} \mid \omega_{j}^{h}, W_{j t}\right)=0, \omega_{j}^{h}, \lambda_{h}$, and $\eta_{j t}^{h}$ can be consistently estimated.

The idea in testing the different models is thus to infer which cost equation has the best statistical fit given the observed cost shifters $W_{j t}$ that depend on characteristics of the brand of product $j$ and not on the conjectured model. This equation is subject to implicit restrictions, since for example products of the same brand but sold by different retailers will have the same brand characteristics appearing in $W_{j t}$ but different $\operatorname{costs} C_{j t}^{h}$. For example, we denote brand name the variable $W_{j t}^{n}$ for two products $j$ and $j$ ' of the same brand but sold in different retailers, we have $W_{j t}^{n}=W_{j^{\prime} t}^{n}$ while $C_{j t}^{h}$ and $C_{j^{\prime} t}^{h}$ are not necessarily equal.

Now, for any two models $h$ and $h^{\prime}$, one would like to test one model against the other, that is test between

$$
p_{j t}=\Gamma_{j t}^{h}+\gamma_{j t}^{h}+\left[\exp \left(\omega_{j}^{h}+W_{j t}^{\prime} \lambda_{h}\right)\right] \eta_{j t}^{h}
$$

and

$$
p_{j t}=\Gamma_{j t}^{h^{\prime}}+\gamma_{j t}^{h^{\prime}}+\left[\exp \left(\omega_{j}^{h^{\prime}}+W_{j t}^{\prime} \lambda_{h^{\prime}}\right)\right] \eta_{j t}^{h^{\prime}} .
$$

Using non-linear least squares, we implement the following:

$$
\min _{\lambda_{h}, \omega_{j}^{h}} Q_{n}^{h}\left(\lambda_{h}, \omega_{j}^{h}\right)=\min _{\lambda_{h}, \omega_{j}^{h}} \frac{1}{n} \sum_{j, t}\left(\ln \eta_{j t}^{h}\right)^{2}=\min _{\lambda_{h}, \omega_{j}^{h}} \frac{1}{n} \sum_{j, t}\left[\ln \left(p_{j t}-\Gamma_{j t}^{h}-\gamma_{j t}^{h}\right)-\omega_{j}^{h}-W_{j t}^{\prime} \lambda_{h}\right]^{2}
$$

Non-nested tests (Vuong, 1989, and Rivers and Vuong, 2002) are then applied to infer which model $h$ is statistically the best. This involves testing models against each other. The test of Vuong (1989) applies in the context of maximum likelihood estimation and thus would apply in our case if log-normality of $\eta_{j t}^{h}$ is assumed. Rivers and Vuong (2002) generalized this kind of test to a broad class of estimation methods including nonlinear least squares. Moreover, the Vuong (1989) or the Rivers and Vuong (2002) approaches do not require that either competing model be correctly specified under the tested null hypothesis. Indeed, other approaches such as Cox's tests (see, among others, Smith, 1992) require such an assumption, i.e. that one of the competing models accurately describes the data. This assumption cannot be sustained when dealing with a real data set in the present case. 
Taking any two competing models $h$ and $h^{\prime}$, the null hypothesis is that the two nonnested models are asymptotically equivalent when

$$
H_{0}: \lim _{n \rightarrow \infty}\left\{\bar{Q}_{n}^{h}\left(\bar{\lambda}_{h}, \bar{\omega}_{j}^{h}\right)-\bar{Q}_{n}^{h^{\prime}}\left(\bar{\lambda}_{h^{\prime}}, \bar{\omega}_{j}^{h^{\prime}}\right)\right\}=0
$$

where $\bar{Q}_{n}^{h}\left(\bar{\lambda}_{h}, \bar{\omega}_{j}^{h}\right)\left(\right.$ resp. $\left.\bar{Q}_{n}^{h^{\prime}}\left(\bar{\lambda}_{h^{\prime}}, \bar{\omega}_{j}^{h^{\prime}}\right)\right)$ is the expectation of a lack-of-fit criterion $Q_{n}^{h}\left(\lambda_{h}, \omega_{j}^{h}\right)$ (i.e. the opposite of a goodness-of-fit criterion) evaluated for model $h$ (resp. $h^{\prime}$ ) at the pseudo-true values of the parameters of this model, denoted by $\bar{\lambda}_{h}, \bar{\omega}_{j}^{h}\left(\right.$ resp. $\left.\bar{\lambda}_{h^{\prime}}, \bar{\omega}_{j}^{h^{\prime}}\right)$. The first alternative hypothesis is that $h$ is asymptotically better than $h^{\prime}$ when

$$
H_{1}: \lim _{n \rightarrow \infty}\left\{\bar{Q}_{n}^{h}\left(\bar{\lambda}_{h}, \bar{\omega}_{j}^{h}\right)-\bar{Q}_{n}^{h^{\prime}}\left(\bar{\lambda}_{h^{\prime}}, \bar{\omega}_{j}^{h^{\prime}}\right)\right\}<0
$$

Similarly, the second alternative hypothesis is that $h^{\prime}$ is asymptotically better than $h$ when

$$
H_{2}: \lim _{n \rightarrow \infty}\left\{\bar{Q}_{n}^{h}\left(\bar{\lambda}_{h}, \bar{\omega}_{j}^{h}\right)-\bar{Q}_{n}^{h^{\prime}}\left(\bar{\lambda}_{h^{\prime}}, \bar{\omega}_{j}^{h^{\prime}}\right)\right\}>0
$$

The test statistic $T_{n}$ captures the statistical variation that characterizes the sample values of the lack-of-fit criterion and is then defined as a suitably normalized difference of the sample lack-of-fit criteria, i.e.

$$
T_{n}=\frac{\sqrt{n}}{\hat{\sigma}_{n}^{h h^{\prime}}}\left\{Q_{n}^{h}\left(\widehat{\lambda}_{h}, \widehat{\omega}_{j}^{h}\right)-Q_{n}^{h^{\prime}}\left(\widehat{\lambda}_{h^{\prime}}, \widehat{\omega}_{j}^{h^{\prime}}\right)\right\}
$$

where $Q_{n}^{h}\left(\widehat{\lambda}_{h}, \widehat{\omega}_{j}^{h}\right)$ (resp. $\left.Q_{n}^{h^{\prime}}\left(\widehat{\lambda}_{h^{\prime}}, \widehat{\omega}_{j}^{h^{\prime}}\right)\right)$ is the sample lack-of-fit criterion evaluated for model $h\left(\right.$ resp. $\left.h^{\prime}\right)$ at the estimated values of the parameters of this model, denoted by $\widehat{\lambda}_{h}, \widehat{\omega}_{j}^{h}$ (resp. $\left.\widehat{\lambda}_{h^{\prime}}, \widehat{\omega}_{j}^{h^{\prime}}\right) . \hat{\sigma}_{n}^{h h^{\prime}}$ denotes the estimated value of the variance of the difference in lack-of-fit. Since our models are strictly non-nested, Rivers and Vuong showed that the asymptotic distribution of the $T_{n}$ statistic is standard normal distribution. The selection procedure involves comparing the sample value of $T_{n}$ with critical values of the standard normal distribution ${ }^{9}$. In the empirical section, evidence based on these different statistical tests will be presented.

\footnotetext{
${ }^{9}$ If $\alpha$ denotes the desired size of the test and $t_{\alpha / 2}$ the value of the inverse standard normal distribution evaluated at $1-\alpha / 2$. If $T_{n}<t_{\alpha / 2} H_{0}$ is rejected in favor of $H_{1}$; if $T_{n}>t_{\alpha / 2} H_{0}$ is rejected in favor of $H_{2}$. Otherwise, $H_{0}$ is not rejected.
} 


\section{Econometric Estimation and Test Results}

\subsection{Demand Results}

We estimated the demand model presented in section 4 , as well as a standard multinomial logit model. The estimates of the random-coefficients logit (RCL) model and the simple multinomial logit (ML) are in Table 4 (the results of the first stage of this demand estimates are given in appendix 8.5). The simple multinomial logit model is estimated using TwoStage least squares with the same kind of instrumental variables.

\begin{tabular}{lccc}
\hline \hline Coefficients (Std. error) & ML & RCL & RCL \\
& & & $\begin{array}{c}\text { Robustness check } \\
(3)\end{array}$ \\
\hline \hline Price $(-\alpha)$ & $-5.47(0.44)$ & $-8.95(1.14)$ & $-10.74(1.45)$ \\
Price $(\sigma)$ & & $2.04(0.81)$ & $3.61(1.20)$ \\
Std dev. of Price & & & $0.81(1.13)$ \\
Average distance & & & $0.03(0.06)$ \\
Coefficients $\beta_{j}, \gamma_{t}$ not shown & & & \\
Overidentifying restrictions test & $6.30\left(\chi^{2}(10)\right)$ & $7.81\left(\chi^{2}(3)\right)$ & $12.50\left(\chi^{2}(8)\right)$ \\
\hline \hline
\end{tabular}

Table 4: Estimation Results of Demand Models

The results show that the price coefficient has the correct sign. In the case of the random coefficients logit model, the price coefficient has a distribution with mean equal to 8.95 and standard deviation equal to 2.04. This implies that an infinitesimal part of the distribution of the coefficient $\alpha_{i}$ is negative. In both estimations, all the $54 \beta_{j}$ and $39 \gamma_{t}$ coefficients are not shown to save space. As Table 4 shows, the overidentifying restrictions tests are not rejected. Also, we have checked after estimation that $\xi_{j t}$ is not serially correlated. Actually, the first and the second order serial correlations is equal to 0.019 with a standard error of 0.02 and to 0.016 with standard error of 0.02 , respectively, which proves that it is not significantly different from zero.

As we said in section 2, the aggregate data come from the aggregation of a household survey and thus aggregation problems may raise some questions about the demand results. To ensure the reliability of our demand model, we conducted several specification tests before reaching the specification shown in Table 4. We also tried to investigate the question of possibly downward biased average prices by testing the robustness of our demand model with the following method. First, we computed the observed variance of each product price 
across purchases for any given month and introduced this product characteristic into the demand model. If our average prices are downward biased, this bias is likely to be positively correlated with the within month and across stores variance of the price for a product. Then, introducing this characteristic in the demand model, we should expect a positive coefficient. This is what is found but the coefficient is small (0.809) and far from significant (its standard error being 1.14). Moreover, when this variable is introduced, it does not significantly change the estimates of our price coefficients $\alpha$ and $\sigma$. The same approach was applied by using the distance from home to the retailer obtained with the observation of the location of the all supermarkets in France using LSA data, and using zip codes for households and geographical data on distances. The average distance of purchasers of each product at each month was calculated and introduced as a characteristic. Again, the other parameters of the demand model did not change significantly and the coefficient of this variable did not appear significant (its estimate was 0.031 with a standard error of 0.059 ). This was true whether introducing these variables jointly or not. Column (3) of Table 4 shows the results when both variables are introduced. Finally, we assessed the robustness of the simplification amounting to consider the most important brands (in terms of market share) by adding the next most important one. Adding one brand, whose market share is on average $0.022 \%$ only, the results of the random coefficients logit model did not change significantly. The price coefficient was 9.8 and the coefficient of heterogeneity of tastes was 2.7. Moreover, with all these alternative specifications, the empirical results of interest that appear in the following did not change significantly.

Given the demand estimates, it is interesting to note that we find estimates of unobserved product specific mean utilities $\beta_{j}$ are found. Using these parameter estimates, their correlation with observed product characteristics can be considered using regression estimates. This is shown in Table 5 below. 


\begin{tabular}{lcc}
\hline \hline \multicolumn{3}{l}{ GLS regression (with robust standard errors) } \\
\hline \multicolumn{2}{l}{ Dependent Variable : Fixed Effects $\beta_{j}$} \\
\hline \hline Explanatory variables & Coefficient (Std. error) & Coefficient (Std. error) \\
Mineral Water $(0 / 1)$ & $-2.76(0.11)$ & $4.71(0.18)$ \\
Minerality & $0.70(0.05)$ & $0.19(0.08)$ \\
Manufacturer 1 & $6.14(0.10)$ & \\
Manufacturer 2 & $5.53(0.10)$ & \\
Manufacturer 3 & $-4.44(0.09)$ & $-0.85(0.18)$ \\
Brand 3 & & $-1.57(0.20)$ \\
Brand 4 & & $-0.87(0.17)$ \\
Brand 5 & & $-3.00(0.18)$ \\
Brand 6 & & $-7.26(0.17)$ \\
Brand 7 & $0.26(0.18)$ \\
Retailer 2 & $-0.71(0.17)$ \\
Retailer 3 & & $0.20(0.18)$ \\
Retailer 4 & & $0.25(0.18)$ \\
Retailer 5 & & $-0.35(0.18)$ \\
Retailer 6 & & $-0.13(0.18)$ \\
Retailer 7 & & $2.59(0.18)$ \\
Constant & & $308.12(0.00)$ \\
\hline$F$ test $(p$ value) & $3576.20(0.00)$ & \\
\hline \hline
\end{tabular}

Table 5: Regression of fixed effects on the product characteristics

The first column of Table 5 shows that the product specific constant mean utility $\beta_{j}$ is increasing with the minerality of water and that the identity of the manufacturer of the bottled water affects this mean utility. The second column of Table 5 shows that controlling for brand effects is very important and that, everything else equal, the mean utility is larger for mineral water rather than spring water (while it is the contrary if one does not control for brand effects as in column 1). This is probably due to image, reputation and advertising at the retail and brand levels.

Finally, once the structural demand estimates have been obtained, price elasticities of demand for each differentiated product can be calculated. Table 6 shows the average elasticities for different groups of products. 


\begin{tabular}{|c|c|c|c|c|}
\hline Elasticities $\left(\eta_{j k}\right)$ & \multicolumn{4}{|c|}{ Random Coefficients Logit } \\
\hline & Own-p & ce elasticity & Cross- & ce elasticity \\
\hline All bottle water & $\begin{array}{c}\text { Mean } \\
-10.12\end{array}$ & $\begin{array}{l}\text { Std. Dev. } \\
2.65\end{array}$ & $\begin{array}{c}\text { Mean } \\
0.05\end{array}$ & $\begin{array}{c}\text { Std. Dev. } \\
0.02\end{array}$ \\
\hline Mineral water & -11.38 & 1.59 & 0.06 & 0.01 \\
\hline Spring water & -6.64 & 1.71 & 0.03 & 0.01 \\
\hline $\begin{array}{l}1 \\
2 \\
3 \\
4 \\
5 \\
6 \\
7 \\
8\end{array}$ & $\begin{array}{c}-11.92 \\
-12.96 \\
-11.66 \\
-10.44 \\
-11.00 \\
-4.97 \\
-8.10 \\
-8.23\end{array}$ & $\begin{array}{l}0.98 \\
0.39 \\
1.53 \\
0.49 \\
0.48 \\
0.32 \\
1.04 \\
0.60\end{array}$ & $\begin{array}{l}0.06 \\
0.03 \\
0.05 \\
0.07 \\
0.10 \\
0.03 \\
0.03 \\
0.08\end{array}$ & $\begin{array}{l}0.03 \\
0.02 \\
0.02 \\
0.03 \\
0.04 \\
0.01 \\
0.01 \\
0.03\end{array}$ \\
\hline $\begin{array}{l}1 \\
2 \\
3 \\
4 \\
5 \\
6 \\
7\end{array}$ & $\begin{array}{c}-9.86 \\
-10.21 \\
-10.03 \\
-9.92 \\
-9.61 \\
-10.44 \\
-10.23\end{array}$ & $\begin{array}{l}2.47 \\
2.65 \\
2.83 \\
2.35 \\
2.56 \\
2.62 \\
2.73\end{array}$ & $\begin{array}{l}0.06 \\
0.07 \\
0.02 \\
0.11 \\
0.10 \\
0.04 \\
0.03\end{array}$ & $\begin{array}{l}0.02 \\
0.02 \\
0.01 \\
0.04 \\
0.03 \\
0.01 \\
0.01\end{array}$ \\
\hline
\end{tabular}

Table 6: Summary of Elasticities Estimates

On average, the own price elasticity is -10.1 and appears to be almost double for mineral water rather than for spring water (brands 6 and 8). Mineral water products seem then to be more sensitive to changes in its prices than spring water products. This implies that manufacturers and retailers margins for spring water products will be higher (and almost the double) than for mineral water products. Differences between brands and between retailers also exist and thus elasticities also vary across products within the spring water or mineral water categories. Cross-price elasticities are positive but much less so in absolute value, which is not surprising given the number of products obtained by allowing products to differ not only by brand but also by retailer. These cross-price elasticities do vary across brands and retailers and standard deviations show that they vary across brands at a same retailer or across retailers for a given brand. Standard deviations of own-price elasticities show that they do vary more across brands at a given retailer than across retailer for a given brand. 


\subsection{Price-Cost Margins}

Once demand parameters have been estimated, we obtain the price cost margins at the retailer and manufacturer levels or total price cost margins for all products, under the various scenarios considered. Each scenario can be described according to the assumptions made on the manufacturers' behavior (collusive or Nash), the retailers' behavior (collusive or Nash) and the vertical interaction which can be Stackelberg or Nash under double marginalization or RPM or not under two part tariff contracts. The models described in the following Table are considered, where the producer is always a Stackelberg under nonlinear contracts.

\begin{tabular}{lccc}
\hline \hline Models & $\begin{array}{c}\text { Retailer } \\
\text { Behavior }\end{array}$ & $\begin{array}{c}\text { Manufacturer } \\
\text { Behavior }\end{array}$ & $\begin{array}{c}\text { Vertical } \\
\text { Interaction }\end{array}$ \\
\hline Double marginalization & Collusion & Nash & Nash \\
Model 1 & Collusion & Nash & Stackelberg \\
Model 2 & Collusion & Collusion & Nash \\
Model 3 & Collusion & Collusion & Stackelberg \\
Model 4 & Nash & Nash & Nash \\
Model 5 & Nash & Nash & Stackelberg \\
Model 6 & Nash & Collusion & Nash \\
Model 7 & Nash & Collusion & Stackelberg \\
Model 8 & & & RPM $(w=\mu)$ \\
Two Part Tariffs & Nash & Nash & RPM $(p=w+c)$ \\
Model 9 & Nash & Nash & RPM $(p=w+c)$ \\
Model 10 & Collusion & Collusion & RPM \\
Model 11 & Nash & Nash & no RM \\
Model 12 & \multicolumn{3}{c}{} \\
\hline \hline
\end{tabular}

Note that in the case of private labels products, it is assumed that the retailer is also the producer, which amounts in our models to assuming that the behavior for pricing private labels is equivalent to that of a manufacturer perfectly colluding with the retailer for that good. Of course, only the total price cost margin is then computed for these private label goods because it then becomes meaningless to compute wholesale price and retail price margins separately. 


\begin{tabular}{|c|c|c|c|c|c|}
\hline \multirow{2}{*}{\multicolumn{2}{|c|}{ Price-Cost Margins (\% of retail price $p$ ) }} & \multicolumn{2}{|c|}{ Mineral Water } & \multicolumn{2}{|c|}{ Spring Water } \\
\hline & & Mean & Std. Dev. & Mean & Std. Dev. \\
\hline \multicolumn{6}{|c|}{ Double Marginalization } \\
\hline \multirow[t]{3}{*}{ Model 1} & Retailers & 13.48 & 1.43 & 19.80 & 3.60 \\
\hline & Manufacturers & 9.90 & 0.77 & 20.62 & 1.13 \\
\hline & Total & 23.07 & 1.67 & 43.91 & 2.16 \\
\hline \multirow[t]{3}{*}{ Model 2} & Retailers & 13.48 & 1.44 & 19.80 & 3.60 \\
\hline & Manufacturers & 9.77 & 0.64 & 19.02 & 1.09 \\
\hline & Total & 22.94 & 1.50 & 42.31 & 2.11 \\
\hline \multirow[t]{3}{*}{ Model 3} & Retailers & 13.48 & 1.43 & 19.80 & 3.60 \\
\hline & Manufacturers & 11.99 & 0.88 & 22.32 & 1.04 \\
\hline & Total & 25.10 & 1.84 & 45.61 & 2.11 \\
\hline \multirow[t]{3}{*}{ Model 4} & Retailers & 13.48 & 1.43 & 19.80 & 3.60 \\
\hline & Manufacturers & 12.76 & 0.75 & 21.35 & 0.97 \\
\hline & Total & 25.94 & 1.69 & 44.63 & 2.03 \\
\hline \multirow[t]{3}{*}{ Model 5} & Retailers & 9.45 & 1.48 & 16.49 & 4.06 \\
\hline & Manufacturers & 9.90 & 0.77 & 20.62 & 1.13 \\
\hline & Total & 19.02 & 1.65 & 41.05 & 2.19 \\
\hline \multirow[t]{3}{*}{ Model 6} & Retailers & 9.45 & 1.48 & 16.49 & 4.06 \\
\hline & Manufacturers & 10.53 & 4.12 & 20.20 & 1.95 \\
\hline & Total & 19.66 & 4.22 & 40.64 & 2.56 \\
\hline \multirow[t]{3}{*}{ Model 7} & Retailers & 9.45 & 1.48 & 16.49 & 4.06 \\
\hline & Manufacturers & 11.93 & 0.88 & 22.32 & 1.04 \\
\hline & Total & 21.05 & 1.73 & 42.75 & 2.09 \\
\hline \multirow[t]{3}{*}{ Model 8} & Retailers & 9.45 & 1.48 & 16.49 & 4.06 \\
\hline & Manufacturers & 13.42 & 2.96 & 22.75 & 3.79 \\
\hline & Total & 22.54 & 3.04 & 43.19 & 3.96 \\
\hline \multicolumn{6}{|c|}{ Two part Tariffs with RPM } \\
\hline Model 9 & Nash and $w=\mu$ & 12.90 & 1.03 & 17.87 & 5.29 \\
\hline Model 10 & Nash and $p=w+c$ & 10.85 & 1.06 & 16.70 & 4.61 \\
\hline Model 11 & Collusion and $p=w+c$ & 12.93 & 1.03 & $\mathbf{1 7 . 9 5}$ & 5.20 \\
\hline \multicolumn{6}{|c|}{ Two-part Tariffs without RPM } \\
\hline \multirow[t]{3}{*}{ Model 12} & Retailers & 9.45 & 1.48 & 16.49 & 4.06 \\
\hline & Manufacturers & 2.94 & 1.13 & 1.93 & 0.43 \\
\hline & Total & 12.07 & 1.36 & 22.45 & 1.04 \\
\hline
\end{tabular}

Table 7: Estimated Price-Cost Margins

Table 7 then shows the averages ${ }^{10}$ of product level price cost margin estimates under the different models with the random-coefficients logit demand. It is worth noting that price cost margins are generally lower for mineral water than for spring water. As expected, it can be seen that total price-cost margins are much lower for two-part tariff models than for linear pricing models. Although the most significant source of variation in margins

\footnotetext{
${ }^{10}$ Note that the average price-cost margin at retailer level plus the average price-cost margin at manufacturer level do not sum to the total price cost margin because of the private labels products for which no price cost margin at manufacturer level is computed, the retailer price cost margin being equal to the total price cost margin.
} 
lies in the comparison of linear versus nonlinear pricing models, margins still vary quite substantially among linear pricing models only or among two-part tariff models. Under linear pricing, when there is no collusion at the retailer level, retailers' margins are on average smaller than manufacturers' margins but still quite high for the food retailing sector.

It is to be noted that the flexibility of the random coefficients logit model allows estimated margins to vary across retailers for a given brand and across brands for a given retailer. The Table 8 in the following shows the average price-cost margins and the average variances of these margins across retailers for a given brand or across brands for a given retailers for the model of two part tariffs with resale price maintenance (Model 10) which will be the preferred model according non-nested tests results in the next section. It appears clearly that these margins do vary in all dimensions ${ }^{11}$. The column (Std. Dev.) shows that average across periods of the standard deviations of margins across products of the same brand or the same retailer. It shows that estimated margins do vary across products and not only across periods. The flexibility of the random coefficients logit model is demonstrated here by the fact that margins vary across products.

\begin{tabular}{rcc}
\hline \hline Model & \multicolumn{2}{c}{ Two Part Tariffs with RPM } \\
& Mean & Std. Dev. \\
\hline Retailer & & \\
1 & 12.48 & 4.05 \\
2 & 12.23 & 3.55 \\
3 & 12.58 & 4.01 \\
4 & 12.47 & 3.69 \\
5 & 12.87 & 3.88 \\
6 & 12.11 & 3.88 \\
7 & 12.17 & 3.92 \\
\hline Brand & & \\
1 & 10.16 & 0.44 \\
2 & 9.89 & 0.16 \\
3 & 10.84 & 0.55 \\
4 & 11.31 & 0.35 \\
5 & 11.21 & 0.30 \\
6 & 21.21 & 0.99 \\
7 & 12.62 & 1.69 \\
8 & 12.23 & 0.81 \\
\hline \hline
\end{tabular}

\footnotetext{
${ }^{11}$ This is also true for wholesale and retail level margins when they can be identified as in double marginalization models or in two-part tariffs without resale price maintenance.
} 
Table 8: Variations of estimated margins across products (percent or retail price)

\subsection{Estimates of cost equations and nonnested tests}

After estimating the different price cost margins for the models considered, the marginal $\operatorname{cost} C_{j t}^{h}$ can be derived using equation (12) and we then estimate cost equations. Table 9 shows the empirical results of estimation of the cost equation (13) for $h=1, \ldots, 12$ that is

$$
\ln C_{j t}^{h}=\omega_{j}^{h}+W_{j t} \lambda_{g}+\ln \eta_{j t}^{h}
$$

where $\omega_{j}^{h}$ is a product specific fixed effect, variables $W_{j t}$ include time dummies $\delta_{t}$, wages, oil, diesel fuel, packaging material and plastic price variables interacted with the dummy variable for spring water $(S W)$ and mineral water $(M W)$.

\begin{tabular}{|c|c|c|c|c|c|c|}
\hline \begin{tabular}{l}
\multicolumn{1}{c}{$\ln C_{j t}^{h}$} \\
Coeff. (Std. err.)
\end{tabular} & Model 1 & Model 2 & Model 3 & Model 4 & Model 5 & Model 6 \\
\hline salary $\times S W$ & $0.03(0.21)$ & $0.04(0.20)$ & $-0.02(0.21)$ & $-0.02(0.21)$ & $0.12(0.21)$ & $-0.01(0.22)$ \\
\hline salary $\times M W$ & $0.16(0.18)$ & $0.16(0.18)$ & $0.10(0.18)$ & $0.09(0.18)$ & $0.25(0.18)$ & $0.08(0.23)$ \\
\hline plastic $\times S W$ & $-0.02(0.09)$ & $-0.02(0.09)$ & $-0.02(0.09)$ & $-0.03(0.09)$ & $-0.02(0.09)$ & $-0.07(0.11)$ \\
\hline plastic $\times M W$ & $-0.02(0.08)$ & $-0.01(0.08)$ & $-0.02(0.08)$ & $-0.02(0.08)$ & $-0.02(0.08)$ & $-0.10(0.10)$ \\
\hline packaging $\times S W$ & $0.11(0.05)$ & $0.11(0.05)$ & $0.12(0.05)$ & $0.12(0.05)$ & $0.08(0.05)$ & $0.13(0.07)$ \\
\hline packaging $\times M W$ & $0.10(0.05)$ & $0.10(0.05)$ & $0.11(0.05)$ & $0.11(0.05)$ & $0.07(0.05)$ & $0.10(0.06)$ \\
\hline diesel $\times S W$ & $0.05(0.02)$ & $0.03(0.03)$ & $0.03(0.03)$ & $0.03(0.03)$ & $0.03(0.03)$ & $0.04(0.03)$ \\
\hline diesel $\times M W$ & $0.03(0.03)$ & $0.05(0.02)$ & $0.05(0.02)$ & $0.05(0.02)$ & $0.06(0.02)$ & $0.09(0.02)$ \\
\hline oil $\times S W$ & $-0.02(0.03)$ & $-0.02(0.03)$ & $-0.02(0.03)$ & $-0.02(0.04)$ & $-0.01(0.03)$ & $-0.04(0.04)$ \\
\hline oil $\times M W$ & $-0.05(0.02)$ & $-0.05(0.02)$ & $-0.05(0.02)$ & $-0.05(0.02)$ & $-0.05(0.02)$ & $-0.11(0.03)$ \\
\hline constant & $-2.05(2.00)$ & $-2.06(1.97)$ & $-1.59(2.01)$ & $-1.42(1.99)$ & $-2.62(1.98)$ & $-0.78(2.45)$ \\
\hline All $\delta_{t}=0 F$ test ( $p$ val. $)$ & $2.89(0.00)$ & $2.86(0.00)$ & $3.00(0.00)$ & $2.96(0.00)$ & $2.75(0.001)$ & $3.59(0.00)$ \\
\hline All $\omega_{j}^{h}=0 F$ test ( $p$ val. $)$ & $490.1(0.00)$ & $480.4(0.00)$ & $499.5(0.00)$ & $493.9(0.00)$ & $493.8(0.00)$ & $320.4(0.00)$ \\
\hline
\end{tabular}

Table 9 : Cost Equations for the Random Coefficients Logit Model

\begin{tabular}{|c|c|c|c|c|c|c|}
\hline $\begin{array}{c}\ln C_{j t}^{h} \\
\text { Coeff. (Std. err.) }\end{array}$ & Model 7 & Model 8 & Model 9 & Model 10 & Model 11 & Model 12 \\
\hline salary $\times S W$ & $0.07(0.21)$ & $0.04(0.21)$ & $0.06(0.19)$ & $0.12(0.19)$ & $0.08(0.17)$ & $0.11(0.19)$ \\
\hline salary $\times M W$ & $0.20(0.18)$ & $0.06(0.18)$ & $0.18(0.17)$ & $0.24(0.17)$ & $0.20(0.17)$ & $0.20(0.17)$ \\
\hline plastic $\times S W$ & $-0.02(0.09)$ & $-0.05(0.09)$ & $-0.01(0.08)$ & $-0.02(0.09)$ & $-0.02(0.09)$ & $-0.04(0.08)$ \\
\hline plastic $\times M W$ & $-0.02(0.08)$ & $-0.05(0.08)$ & $-0.01(0.08)$ & $-0.02(0.08)$ & $-0.02(0.08)$ & $-0.07(0.08)$ \\
\hline packaging $\times S W$ & $0.09(0.05)$ & $0.10(0.05)$ & $0.10(0.05)$ & $0.08(0.05)$ & $0.09(0.05)$ & $0.10(0.05)$ \\
\hline packaging $\times M W$ & $0.08(0.05)$ & $0.09(0.05)$ & $0.09(0.04)$ & $0.06(0.04)$ & $0.07(0.04)$ & $0.09(0.04)$ \\
\hline diesel $\times S W$ & $0.03(0.03)$ & $0.03(0.03)$ & $0.03(0.03)$ & $0.03(0.02)$ & $0.03(0.03)$ & $0.03(0.03)$ \\
\hline diesel $\times M W$ & $0.05(0.02)$ & $0.06(0.02)$ & $0.05(0.02)$ & $0.05(0.02)$ & $0.05(0.02)$ & $0.07(0.02)$ \\
\hline oil $\times S W$ & $-0.02(0.03)$ & $-0.03(0.03)$ & $-0.01(0.03)$ & $-0.01(0.03)$ & $-0.01(0.03)$ & $-0.03(0.03)$ \\
\hline oil $\times M W$ & $-0.04(0.02)$ & $-0.09(0.05)$ & $-0.05(0.02)$ & $-0.04(0.02)$ & $-0.04(0.02)$ & $-0.07(0.03)$ \\
\hline constant & $-2.19(1.99)$ & $-0.94(2.02)$ & $-2.06(1.85)$ & $-2.39(1.85)$ & $-2.05(1.84)$ & $-1.74(1.89)$ \\
\hline All $\delta_{t}=0 F$ test ( $p$ val. $)$ & $2.68(0.001)$ & $2.68(0.001)$ & $2.96(0.000)$ & $2.80(0.001)$ & $2.76(0.001)$ & $3.54(0.000)$ \\
\hline All $\omega_{j}^{h}=0 F$ test ( $p$ val. $)$ & $504.1(0.00)$ & $489.2(0.00)$ & $395.6(0.00)$ & $390.5(0.00)$ & $392.9(0.00)$ & $299.7(0.00)$ \\
\hline
\end{tabular}

Table 9 (continued): Cost Equations for the Random Coefficients Logit Model 
The results of these cost equations are useful mostly in order to test which model best fits the data. However, it is interesting to see that even if product level dummies and period dummies are highly significant, other explanatory variables are also worthy of note. In particular, the packaging cost variable is almost always significant, while oil and diesel price indices are also quite often significant. Salary indices and plastic cost variables are never significant at the $5 \%$ conventional level. Finally, the significance of these variable cost shifters vary across equations, that is across models. The coefficients of the cost shifters are always of the same sign across models but the absolute values of these coefficients can vary from one to four across models.

The Rivers and Vuong non-nested tests explained in section 4.2 were then performed. The results are given in Table 10. In order to take into account the fact that each cost equation uses cost estimates that have been estimated after the estimation of the demand model, the bootstrap was used. The statistics of test ${ }^{12}$ shown in Table 10 are thus bootstrap statistics with 500 replications. Statistics in parentheses are standard deviations of the test statistic over the replications. Even if tests need not be transitive, we can see that model 10 is the best because its column statistic estimates are always negative and lower than the $5 \%$ negative critical value of a normal test that $T_{n}$ is different from zero while the row statistic if higher than the $5 \%$ positive critical value. The Vuong (1989) tests based on the maximum likelihood estimation of the cost equations under normality provides the same inference concerning the best model (see Table 13 in appendix 8.6).

\footnotetext{
${ }^{12}$ Recall that for a $5 \%$ size of the test, $H_{0}$ is rejected in favor of $H_{2}$ if $T_{n}$ is lower than the critical value -1.64 and that $H_{0}$ is rejected in favor of $H_{1}$ if $T_{n}$ is higher than the critical value 1.64.
} 


\begin{tabular}{|c|c|c|c|c|c|c|c|c|c|c|c|}
\hline \multicolumn{8}{|c|}{ Rivers and Vuong Test Statistic $T_{n}=\frac{\sqrt{n}}{\widehat{\sigma}_{n}}\left(Q_{n}^{2}\left(\hat{\Theta}_{n}^{2}\right)-Q_{n}^{1}\left(\hat{\Theta}_{n}^{1}\right)\right.$} & \multicolumn{4}{|c|}{$\rightarrow N(0,1)$} \\
\hline$\searrow$ & $\mathrm{H}_{2}$ & & & & & & & & & & \\
\hline$H_{1}$ & 2 & 3 & 4 & 5 & 6 & 7 & 8 & 9 & 10 & 11 & 12 \\
\hline 1 & $\begin{array}{l}-8.33 \\
(5.88)\end{array}$ & $\begin{array}{c}6.60 \\
(3.93)\end{array}$ & $\begin{array}{l}-1.47 \\
(7.32)\end{array}$ & $\begin{array}{l}-5.75 \\
(3.14)\end{array}$ & $\begin{array}{c}1.94 \\
(3.53)\end{array}$ & $\begin{array}{l}-3.92 \\
(3.19)\end{array}$ & $\begin{array}{c}2.00 \\
(3.45)\end{array}$ & $\begin{array}{l}-8.07 \\
(2.76)\end{array}$ & $\begin{array}{c}-8.19 \\
(2.73)\end{array}$ & $\begin{array}{r}-7.99 \\
(2.73)\end{array}$ & $\begin{array}{c}-1.73 \\
(4.94)\end{array}$ \\
\hline 2 & & $\begin{array}{c}8.75 \\
(5.01)\end{array}$ & $\begin{array}{c}6.63 \\
(6.19)\end{array}$ & $\begin{array}{c}2.11 \\
(7.54)\end{array}$ & $\begin{array}{c}2.64 \\
(4.23)\end{array}$ & $\begin{array}{c}6.88 \\
(7.59)\end{array}$ & $\begin{array}{c}2.99 \\
(5.33)\end{array}$ & $\begin{array}{l}-6.51 \\
(4.31)\end{array}$ & $\begin{array}{c}-6.94 \\
(4.24)\end{array}$ & $\begin{array}{r}-6.50 \\
(4.32)\end{array}$ & $\begin{array}{l}-0.84 \\
(6.68)\end{array}$ \\
\hline 3 & & & $\begin{array}{l}-5.08 \\
(8.27)\end{array}$ & $\begin{array}{l}-6.08 \\
(3.93) \\
\end{array}$ & $\begin{array}{c}1.88 \\
(3.80) \\
\end{array}$ & $\begin{array}{l}-5.79 \\
(3.74) \\
\end{array}$ & $\begin{array}{c}1.88 \\
(3.75) \\
\end{array}$ & $\begin{array}{l}-7.88 \\
(3.67) \\
\end{array}$ & $\begin{array}{c}-7.89 \\
(3.65) \\
\end{array}$ & $\begin{array}{r}-7.80 \\
(3.70) \\
\end{array}$ & $\begin{array}{c}-1.74 \\
(5.10) \\
\end{array}$ \\
\hline 4 & & & & $\begin{array}{l}-1.60 \\
(7.29)\end{array}$ & $\begin{array}{c}1.91 \\
(4.67)\end{array}$ & $\begin{array}{c}0.53 \\
(7.50)\end{array}$ & $\begin{array}{c}2.35 \\
(4.90)\end{array}$ & $\begin{array}{l}-7.22 \\
(4.74)\end{array}$ & $\begin{array}{l}-7.75 \\
(5.05)\end{array}$ & $\begin{array}{r}-7.22 \\
(4.59)\end{array}$ & $\begin{array}{l}-1.41 \\
(6.84)\end{array}$ \\
\hline 5 & & & & & $\begin{array}{c}2.85 \\
(3.30)\end{array}$ & $\begin{array}{c}6.22 \\
(3.43)\end{array}$ & $\begin{array}{c}3.12 \\
(4.52)\end{array}$ & $\begin{array}{l}-8.00 \\
(4.17)\end{array}$ & $\begin{array}{c}-8.50 \\
(3.90)\end{array}$ & $\begin{array}{r}-8.16 \\
(4.46)\end{array}$ & $\begin{array}{c}-1.04 \\
(5.97)\end{array}$ \\
\hline 6 & & & & & & $\begin{array}{l}-2.32 \\
(3.38)\end{array}$ & $\begin{array}{c}0.18 \\
(4.54)\end{array}$ & $\begin{array}{l}-4.95 \\
(3.15)\end{array}$ & $\begin{array}{l}-5.24 \\
(3.60)\end{array}$ & $\begin{array}{r}-4.91 \\
(3.09)\end{array}$ & $\begin{array}{r}-3.58 \\
(4.56)\end{array}$ \\
\hline 7 & & & & & & & $\begin{array}{c}2.61 \\
(3.93)\end{array}$ & $\begin{array}{l}-8.27 \\
(3.90) \\
\end{array}$ & $\begin{array}{c}-8.64 \\
(3.18) \\
\end{array}$ & $\begin{array}{r}-8.33 \\
(4.05) \\
\end{array}$ & $\begin{array}{c}-1.39 \\
(5.49) \\
\end{array}$ \\
\hline 8 & & & & & & & & $\begin{array}{l}-5.59 \\
(4.22)\end{array}$ & $\begin{array}{l}-5.84 \\
(4.96)\end{array}$ & $\begin{array}{l}-5.55 \\
(4.07)\end{array}$ & $\begin{array}{c}-3.68 \\
(3.98)\end{array}$ \\
\hline 9 & & & & & & & & & $\begin{array}{c}-5.09 \\
(4.49)\end{array}$ & $\begin{array}{r}-0.27 \\
(2.84)\end{array}$ & $\begin{array}{c}2.86 \\
(3.92)\end{array}$ \\
\hline 10 & & & & & & & & & & $\begin{array}{c}5.02 \\
(4.72)\end{array}$ & $\begin{array}{c}4.25 \\
(4.59)\end{array}$ \\
\hline 11 & & & & & & & & & & & $\begin{array}{c}2.87 \\
(3.90)\end{array}$ \\
\hline
\end{tabular}

Table 10: Results of the Rivers and Vuong Test (500 Bootstrap replications)

The non-rejected model indicates that manufacturers use two part tariffs with retailers and moreover (as predicted by the theory) that they use resale price maintenance in their contracting relationships although in principle this is not legal in France. In this equilibrium, variable retail margins are zero but total profits including fixed fees are unidentified. It is interesting, however, to note that this equilibrium is such that manufacturers are residual claimants. Zero retail margins also imply that fixed fees paid by retailers to manufacturers are negative if the outside option (reservation profit) of retailers is strictly positive. Thus this model implies that manufacturers pay some sort of slotting allowances to retailers, a practice for which the press often reports evidence in France. Although resale price maintenance is illegal in France, our empirical results show that contractual relationships imply pricing strategies that allow this equilibrium to be replicated. It is worth noting that this pricing equilibrium could be reached through the 
use of two part tariff contracts with resale price maintenance, but it is possible that it is actually implemented through more complex non-linear contracts that would not involve resale price maintenance (Rey and Vergé, 2004). Another possible explanation of this finding is linked to the French regulatory environment about vertical relationships in the supermarket industry and the Galland act passed in 1996 in France (until 2006) which was in action at the time of our data (1998-2000). This law prevented resale-below-cost but this rule could be easily manipulated by manufacturers who would purposely display high wholesale prices in order to prevent retailers to resale at lower prices (because apparently "at loss") while the true wholesale prices were different (because at that time the definition of wholesale prices for the competition agency did not include some costs finally paid by manufacturers such as product placement on store shelves for example).

One main difference introduced by resale price maintenance is that it avoids the double marginalization problem such that empirically, given the demand estimates, what matters for retail prices fixing is the structure of manufacturers' competition and not the retailers' competition (omitting the additional effect of private labels). Of course, this structure does not change in the data, but if one could observe a merger of two retailers, this should not change anything in the strategic choices of manufacturers (if demand stays the same). On the contrary, if there is no RPM, then the retailer industry structure matters since retail prices depend on reaction functions of retailers with respect to wholesale prices (due to the second partial derivatives of market shares with respect to retail prices). The curvature of the demand function thus matters while it is not the case with RPM.

For this preferred model, the estimated total price cost margins (price minus marginal cost of production and distribution), are relatively low with an average of $11 \%$ for mineral water and $17 \%$ for spring water according to the Table 7 . These figures are lower than the rough accounting estimates that can be obtained from aggregate data (see section 2). As Nevo (2001) remarks, the accounting margins only provide an upper bound for the true values. Moreover, the accounting estimates do not take into account the marginal cost of distribution while our structural estimates do. Thus, these empirical results seem 
quite realistic and consistent with the bounds provided by accounting data. In absolute values, the price-cost margins are on average close for mineral and spring waters because mineral water is on average more expensive. Absolute margins are on average $0.037 \in$ for mineral water and $0.025 €$ for spring water. With the best model, average price-cost margins for national brand products versus private labels products can be evaluated. In the case of mineral water, the average price-cost margins for national brands and private labels are not statistically different and about the same with an average of $10.68 \%$ for national brands and $12.61 \%$ for private labels. However, in the case of natural spring water, it appears that price-cost margins for national brands are larger than for private labels with an average of $21.20 \%$ instead of $12.22 \%$.

\section{Simulation of Counterfactual Policy Experiments}

Estimation of the structural demand and cost parameters now allows some counterfactual policy experiments to be simulated. First the method used to simulate these counterfactual policy experiments will be presented, followed by the particular policies and simulation results considered.

The previous estimation and inference allow a vector of marginal costs of production and distribution for the preferred model to be estimated. We denote by $I_{f}, I_{r}$, the true ownership matrices for manufacturers and retailers and $h$ the preferred pricing equilibrium according to the data. We denote $C_{t}=\left(C_{1 t}, . ., C_{j t}, . ., C_{J t}\right)$ the vector of the marginal costs for all products present at time $t$, where $C_{j t}=p_{j t}-\Gamma_{j t}-\gamma_{j t}$. Then, given these marginal costs and the other estimated structural parameters, some policy experiments can be simulated using equilibrium conditions of the supply model considered and using

$I_{f}^{*}$ and $I_{r}^{*}$ the respective ownership matrices of manufacturers and retailers under the counterfactual policy.

Consider the policy experiment where product's ownership has been changed to $I_{f}^{*}$, $I_{r}^{*}$. Equilibrium prices $p_{t}^{*}$ as solutions of the first order equations obtained under the chosen 
policy experiment have to be solved. For example in the case of two part tariffs with RPM:

$$
p_{t}^{*}+\left(I_{f}^{*} S_{p}\left(p_{t}^{*}\right)\right)^{-1} I_{f}^{*} s\left(p_{t}^{*}\right)=C_{t}
$$

Market shares $s\left(p_{t}^{*}\right)$ and their derivatives $S_{p}\left(p_{t}^{*}\right)$ depend of equilibrium prices $p_{t}^{*}$ and the demand model. According to (10), each market share depends on the vector of prices as

$$
s_{j t}\left(p_{t}^{*}\right)=\int_{A_{j t}}\left(\frac{\exp \left(\delta_{j t}^{*}+\mu_{i j t}^{*}\right)}{1+\sum_{k=1}^{J_{t}} \exp \left(\delta_{k t}^{*}+\mu_{i k t}^{*}\right)}\right) \phi\left(v_{i}\right) d v_{i}
$$

which is estimated as $\frac{1}{R} \sum_{r=1}^{R} \frac{\exp \left(\delta_{j t}^{*}+\mu_{r j}^{*}\right)}{1+\sum_{k=1}^{J_{t}} \exp \left(\delta_{k t}^{*}+\mu_{r k t}^{*}\right)}$ where $R$ is the number of draws used to compute the market share by simulation. Moreover, using (11), each element of the matrix of derivatives of the demand $S_{p}\left(p_{t}^{*}\right)$ can be computed as

$$
\frac{\partial s_{j t}}{\partial p_{k t}}=\left\{\begin{array}{cl}
-\int \alpha_{i} s_{i j t}\left(1-s_{i j t}\right) \phi\left(v_{i}\right) d v_{i} & \text { if } j=k \\
\int \alpha_{i} s_{i j t} s_{i k t} \phi\left(v_{i}\right) d v_{i} & \text { otherwise. }
\end{array}\right.
$$

Thus solving the nonlinear equation (14) with respect to the prices $p_{j t}^{*}$, simulated equilibrium prices under such policy are obtained. Market shares are obtained using simulated prices. The solution vector $p_{t}^{*}$ of

$$
\min _{\left\{p_{j t}^{*}\right\}_{j=1, \ldots, J}}\left\|p_{t}^{*}+\left(I_{f}^{*} S_{p}\left(p_{t}^{*}\right)\right)^{-1} I_{f}^{*} s\left(p_{t}^{*}\right)-C_{t}\right\|
$$

is sought where $\|$.$\| is a norm of \mathbb{R}^{J}$. In practice, the Euclidean norm in $\mathbb{R}^{J}$ will be taken.

Given equilibrium prices under the counterfactual policy, the change in consumer surplus $C S_{t}\left(p_{t}\right)-C S_{t}\left(p_{t}^{*}\right)$ can be evaluated using the usual formula for the random coefficients logit model

$$
C S_{t}\left(p_{t}\right)=\frac{1}{\left|\alpha_{i}\right|} E\left[\max _{j} V_{i j t}\left(p_{t}\right)\right]=\frac{1}{\left|\alpha_{i}\right|} \ln \left(\sum_{j=1}^{J} \exp \left[V_{i j t}\left(p_{t}\right)\right]\right) .
$$

Note that the profits of firms are not identified since the equilibrium conditions allow a solution for the prices but not for the fixed fees.

Table 11 shows the results of simulations of different policies. Average effects are presented given that one simulation per period is performed and the standard deviations of all these simulations are shown in parentheses. As the parameters of demand and cost used to perform the simulations are estimated, standard errors of all simulated policies on prices, 
market shares and consumer surplus can be obtained by bootstrap. However, solving the system of equations (15) is already quite long and doing this for each bootstrap replication of the whole estimation and simulation for all periods is extremely time-consuming. The results of the simulation must thus be taken with caution since standard errors are not computed. However, the bootstrap of test statistics and cost equations in the previous section show that the precision of results was fairly robust.

In Table 11, the first simulation considers the case of a de-merger of Nestlé and Perrier. The merger of these companies that occurred in 1992 has been controversial. This merger transferred Contrex from Perrier to Nestlé while Volvic (of Perrier) went over to Danone (BSN). The results of the simulation show that prices would decrease with such a demerger which would suggest that the merger has increased prices. The consumer surplus variation also shows that the merger would have led to a decrease by a little more than $1 \%$. Table 13 also shows the results of the linear pricing case (without changing ownership of products), a supply model where the effect of the double marginalization on retail prices can be clearly seen. Indeed, we see that double marginalization would increase prices of national brands and decrease the private labels ones, consumer surplus would then fall in a large way.

In 1996, the "Galland" Act was introduced. This law requires retailers not to resell under the wholesale price, giving manufacturers the power to impose resale price maintenance by choosing their wholesale price. The Galland Act was removed in 2006 under the assumption that it helped some food industries maintain high prices. One way to see this reform is to consider the case where no resale price maintenance would be used by manufacturers. Simulating the two part tariffs without RPM, we can see that the consumer surplus would increase by $0.8 \%$. On average, prices would decrease for most brands except for private labels. This simulation shows that removing the Galland Act in 2006 should have had beneficial effects on prices for consumers. Using data before and after the implementation of this law, Biscourp, Boutin and Vergé (2008) show with reduced form regressions that this law actually had an inflationary effect on prices in 1996. A result 
which is in line with our policy experiment that can be seen as the dismantling of the Galland Act.

\begin{tabular}{|c|c|c|}
\hline Policy & $\begin{array}{l}\% \text { Change } \\
\text { of price } p_{j t}^{*}\end{array}$ & $\begin{array}{c}\% \text { Change in } \\
\text { market share } s_{j t}^{*}\end{array}$ \\
\hline \multicolumn{3}{|l|}{ Nestlé/Perrier de-merger } \\
\hline Average & $-1.65(0.13)$ & $14.60(1.61)$ \\
\hline Average for Danone (BSN) & $-1.59(0.09)$ & $14.52(1.51)$ \\
\hline Average for Nestlé & $-1.93(0.16)$ & $19.09(2.71)$ \\
\hline Average for Perrier & $-1.80(0.18)$ & $15.98(2.30)$ \\
\hline Average for Castel & $-0.56(0.19)$ & $1.46(1.02)$ \\
\hline Average for Private Labels & $-0.48(0.21)$ & $0.89(1.88)$ \\
\hline Average for outside good & & $-0.21(0.02)$ \\
\hline$\frac{C S_{t}\left(p_{t}\right)-C S_{t}\left(p_{t}^{*}\right)}{C S_{t}\left(p_{t}\right)}$ in $\%$ & \multicolumn{2}{|c|}{$1.35(0.24)$} \\
\hline \multicolumn{3}{|c|}{ Double Marginalization (linear pricing) } \\
\hline Average & $6.73(9.19)$ & $-40.05(56.79)$ \\
\hline Average for Danone & $6.82(6.42)$ & $-52.37(6.33)$ \\
\hline Average for Nestlé & $7.23(7.42)$ & $-54.17(9.24)$ \\
\hline Average for Castel & $15.45(13.51)$ & $-43.09(141.71)$ \\
\hline Average for Private Labels & $-0.47(6.41)$ & $10.82(2.81)$ \\
\hline Average for outside good & & $1.05(0.09)$ \\
\hline$\frac{C S_{t}\left(p_{t}^{*}\right)-C S_{t}\left(p_{t}\right)}{C S_{t}\left(p_{t}\right)}$ in $\%$ & \multicolumn{2}{|c|}{$-13.18(23.24)$} \\
\hline \multicolumn{3}{|c|}{ Two part Tariffs without RPM } \\
\hline Average & $-7.44(5.44)$ & $71.11(50.12)$ \\
\hline Average for Danone & $-7.30(0.66)$ & $78.45(9.33)$ \\
\hline Average for Nestlé & $-7.45(0.85)$ & $82.92(12.15)$ \\
\hline Average for Castel & $-19.05(1.52)$ & $148.75(21.81)$ \\
\hline Average for Private Labels & $0.30(0.16)$ & $-17.99(2.80)$ \\
\hline Average for outside good & & $-2.07(0.42)$ \\
\hline$\frac{C S_{t}\left(p_{t}\right)-C S_{t}\left(p_{t}^{*}\right)}{C S_{t}\left(p_{t}\right)}$ in $\%$ & \multicolumn{2}{|c|}{$0.81(0.39)$} \\
\hline
\end{tabular}

Table 11: Policy experiments results

\section{Conclusion}

In this paper we present the first empirical investigation of a structural model taking into account two part tariff contracts in vertical relationships between manufacturers and retailers in the supermarket industry. Using a particular game form, we test among models of competition between manufacturers and retailers on a differentiated product market. In particular, attention was devoted to two types of nonlinear pricing relationships with two part tariff contracts, with or without resale price maintenance. The method is based on estimates of demand parameters that allow price-cost margins at the manufacturer and retailer levels to be recovered. Testing was then conducted between the different models 
using exogenous variables that are supposed to shift the marginal cost of production and distribution. This methodology was applied to study the market for retailing bottled water in France.

Our empirical analysis implies that manufacturers and retailers use nonlinear pricing contracts and in particular two part tariff contracts with resale price maintenance. We interpret the results under the hypothesis that the "Galland" Act introduced in 1996, which required retailers not to resell under the wholesale price, probably gave manufacturers the power to impose resale price maintenance by choosing their wholesale price. Simulating the two part tariffs without RPM, we find that the consumer surplus would increase by $0.8 \%$. This simulation shows that removing the Galland Act in 2006 should have had beneficial effects on prices for consumers.

This paper's contribution is to allow for estimation of a structural model with a rich set of equilibria under nonlinear contracts. The methodology developed allows different vertical contracting models to be tested in a context of oligopoly both at upstream and downstream levels. For this purpose, as in Rey and Vergé (2004) a game is adopted where upstream firms play first and can make take-it-or-leave-it offers to downstream firms. We leave for further research the analysis of more complex interactions where offers and counter offers could be made in a more dynamic setting. In Gans (2007), orders precede procurement. Downstream firms play first and he shows that even with nonlinear tariffs an oligopolistically competitive outcome is obtained. However, the model of Gans is restricted to an upstream monopolist facing competing downstream firms, which is not true of the framework studied here. In any case, it is true that the models considered are static and that relationship between manufacturers and retailers are in fact repeated. We leave for further research the analysis of dynamic models that will probably be much more complex. Adding the possibility of storage at several stages of the model will also be needed in the future.

Further developments estimating supply models of oligopolistic competition under nonlinear pricing are needed. In particular, further studies are required where assumptions 
of non-constant marginal cost of production and distribution would be allowed. Also, it is clear that more empirical work on other markets will be useful for a better understanding of vertical relationships in the retailing industry. Another research direction that seems promising would involve in developing the present framework to use necessary inequality conditions instead of first order conditions for the identification of bounds on the different margins at the retail and wholesale levels. Rosen's approach (2007) where the strategic interaction is imperfectly known or Pakes et al. (2006) can thus be applied for future research on the framework proposed with two part tariff contracts. Finally, taking into account the endogenous market structure is also an objective that theoretical and empirical research will have to tackle. 


\section{References}

Agreste (1999), Enquête Annuelle d'Entreprise: Résultats Sectoriels et Régionaux 1998,

Paris: Ministère de l'Agriculture et de la Pêche, Données Chiffrées IAA, nº 93

Agreste (2000), Enquête Annuelle d'Entreprise: Résultats Sectoriels et Régionaux 1999, Paris: Ministère de l'Agriculture et de la Pêche, Données Chiffrées IAA, nº100

Agreste (2002), Enquête Annuelle d'Entreprise: Résultats Sectoriels et Régionaux 2000, Paris: Ministère de l'Agriculture et de la Pêche, Données Chiffrées IAA, nº106

Asker, J. (2004) "Measuring Cost Advantages from Exclusive Dealing: An Empirical Study of Beer Distribution," working paper, New York University

Ben-Akiva M. (1974) "Structure of Passenger Travel Demand Models", Transportation research Record, 526, 26-42

Berry, S. (1994) "Estimating Discrete-Choice Models of Product Differentiation", Rand Journal of Economics, 25: 242-262

Berry, S., Levinsohn, J. and A. Pakes (1995) "Automobile Prices in Market Equilibrium", Econometrica, 63: 841-890

Berry S. and A. Pakes (2001), "Additional information for: "Comment on Alternative models of demand for automobiles" by Charlotte Wojcik", Economics Letters, 74, 43-51 Berto Villas-Boas, S. (2007) "Vertical Relationships between Manufacturers and Retailers: Inference with Limited Data", Review of Economic Studies, 74, 625-652.

Biscourp P., Boutin X. and T. Vergé (2008) "The Effects of Retail Regulations on Prices: Evidence from French Data", working paper, CREST Paris.

Brenkers R. and F. Verboven (2006) "Liberalizing a Distribution System: the European Car Market", Journal of the European Economic Association, 4(1), 216-251.

Bresnahan, T. (1987) "Competition and Collusion in the American Automobile Oligopoly: The 1955 Price War", Journal of Industrial Economics, 35, 457-482.

Bresnahan, T. (1989), "Empirical Studies of Industries with Market Power", in R. Schmalensee and R. D. Willig (eds.) Handbook of Industrial Organization, Vol. II (Amsterdam: NorthHolland) 1011-1057. 
Chevalier J., Kashyap and Rossi (2003) "Why Don't Prices Rise during Periods of Peak Demand? Evidence from scanner Data", American Economic Review, 93, 15-37

Compte O., F. Jenny, P. Rey (2002) "Capacity Constraints, Mergers and Collusion", European Economic Review, 46, 1, 1-29

Friberg R. and M. Ganslandt (2003) "Bottle water - a case of pointless trade?", CEPR Discussion Paper No. 4145.

Friberg R. and M. Ganslandt (2003) "Bottle water - a case of pointless trade?", CEPR Discussion Paper No. 4145

Goldberg, P.K. (1995) "Product Differentiation and Oligopoly in International Markets: The Case of the U.S. Automobile Industry", Econometrica, 63, 891-951.

Gans J. (2007) "Vertical Contracting when Competition for Orders Precedes Procurement" Journal of Industrial Economics, 55, 2, 325-346.

Gofti-Laroche L., J.L. Potelon, E. Da Silva and D. Zmirou (2001) "Description of drinking water intake in French communities (E.MI.R.A. study)", Revue d'Epidémiologie et de Santé Publique, 49, 5, 411-422

Goldberg, P.K. and F. Verboven (2001) "The Evolution of Price Dispersion in the European car market", Review of Economic Studies, 68, 811-848.

Hellerstein, R. (2008), "Who Bears the Cost of a Change in the Exchange Rate?" The Journal of International Economics, vol. 76, no. 1, 14-32.

Ho, K. (2006) "The Welfare Effects of Restricted Hospital Choice in the US Medical Care Market", Journal of Applied Econometrics, 21(7): 1039-1079

Ho, K. (2008) "Insurer-Provider Networks in the Medical Care Market", forthcoming American Economic Review

Ivaldi, M. and D. Martimort (1994) "Competition under Nonlinear Pricing", Annales d'Economie et de Statistique, 34, 71-114

Ivaldi, M. and F. Verboven (2005) "Quantifying the Effects from Horizontal Mergers in European Competition Policy", International Journal of Industrial Organization, 23, 9/10, 
$669-691$

Liebowitz, S.J. (1982), "What Do Census Price-Cost Margins Measure?," Journal of Law and Economics, 25: 231-246.

Manuszak, M. D., (2001) "The Impact of Upstream Mergers on Retail Gasoline Markets," working paper, Carnegie Mellon University

McFadden, D. (1978), "Modeling the Choice of Residential Location," in: A. Karlqvist, L. Lundqvist, F. Snickars, and J. Weibull (eds), Spatial Interaction Theory and Planning Models, 75-96, North-Holland: Amsterdam.

McFadden, D., and K. Train (2000) "Mixed MNL Models for Discrete Response" Journal of Applied Econometrics, Vol. 15, No. 5, 447-470.

Mortimer J. (2008) "Vertical Contracts in the Video Rental Industry", The Review of Economic Studies, 75, 165-199

Nevo, A. (1998) "Identification of the Oligopoly Solution Concept in a Differentiated Products Industry", Economics Letters, 59(3), 391-395.

Nevo, A. (2000) "Mergers with Differentiated Products: the Case of the Ready-to-Eat Cereal Industry", RAND Journal of Economics, 31, 395-421.

Nevo, A. (2001) "Measuring Market Power in the Ready-To-Eat Cereal Industry", Econometrica, 69: 307-342.

Nevo, A. and F. Rossi (2008) "An Approach for Extending Dynamic Models to Settings with Multi-Product Firms", Economics Letters, 100, 49-52

Pakes A., Porter J. Ho K. and Ishii J. (2006) "Moment Inequalities and their Applications", mimeo Harvard University

Petrin, A. (2002) "Quantifying the Benefits of New Products: the Case of the Minivan", Journal of Political Economy.

Pinkse, J. and M. Slade (2004) "Mergers, Brand Competition and the Price of a Pint", European Economic Review, 48, 617-643.

Rey, P. and J. Stiglitz (1995) "The role of Exclusive Territories in Producers' Competi- 
tion", RAND Journal of Economics, 26, 3, 431-451.

Rey, P., and J. Tirole (2007) "A Primer on Foreclosure", mimeo, University of Toulouse, Handbook of Industrial Organization, Volume 3, Chapter 7.

Rey, P., and T. Vergé (2004) "Resale Price Maintenance and Horizontal Cartel", CMPO Working Papers series No. 02/047, University of Southampton.

Rivers D. and Q. Vuong (2002) "Model Selection Tests for Nonlinear Dynamic Models" The Econometrics Journal, Vol. 5, issue 1, 1:39

Rosen A. (2007) "Identification and Estimation of Firms' Marginal Cost Functions with Incomplete Knowledge of Strategic Behavior", CeMMAP Working Paper, CWP 03/07, Centre for Microdata Methods and Practice, Institute for Fiscal Studies Rosse, J.N. (1970), "Estimating Cost Function Parameters without Using Cost Data: Illustrated Methodology," Econometrica 38, 2, 256-275.

Slade M. (2004) "Market Power and Joint Dominance in UK Brewing" Journal of Industrial Economics, Vol. 52, 1, 133-163

Smith R. J. (1992) "Non-Nested Tests for Competing Models Estimated by Generalized Methods of Moments", Econometrica, 60, 4, 973-980

Sudhir, K. (2001) "Structural Analysis of Manufacturer Pricing in the Presence of a Strategic Retailer", Marketing Science, 20(3), 244-264.

Verboven, F. (1996) "International Price Discrimination in the European Car Market", RAND Journal of Economics, 27, 240-68.

Villas-Boas, J.M. and Y. Zao (2005) "Retailer, Manufacturers, and Individual Consumers: Modeling the Supply Side in the Ketchup Marketplace", Journal of Marketing Research, $42,83-95$.

Vuong Q. H. (1989) "Likelihood Ratio Tests for Model Selection and Non-Nested Hypotheses", Econometrica, 57, 2, 307-333 


\section{Appendix}

\subsection{Detailed proof of the manufacturers profit expression under two part tariffs}

The theoretical results due to Rey and Vergé (2004) are applied to our context with $F$ firms and $R$ retailers. The participation constraint being binding, we have for all $r$ $\sum_{s \in S_{r}}\left[M\left(p_{s}-w_{s}-c_{s}\right) s_{s}(p)-F_{s}\right]=0$ which implies that

$$
\sum_{s \in S_{r}} F_{s}=\sum_{s \in S_{r}} M\left(p_{s}-w_{s}-c_{s}\right) s_{s}(p)
$$

and thus

$$
\begin{aligned}
\sum_{j \in G_{f}} F_{j}+\sum_{j \notin G_{f}} F_{j} & =\sum_{j=1, ., J} F_{j}=\sum_{r=1, ., R} \sum_{s \in S_{r}} F_{s} \\
& =\sum_{r=1, ., R} \sum_{s \in S_{r}} M\left(p_{s}-w_{s}-c_{s}\right) s_{s}(p)=\sum_{j=1, ., J} M\left(p_{j}-w_{j}-c_{j}\right) s_{j}(p)
\end{aligned}
$$

so that

$$
\sum_{j \in G_{f}} F_{j}=\sum_{j=1, . ., J} M\left(p_{j}-w_{j}-c_{j}\right) s_{j}(p)-\sum_{j \notin G_{f}} F_{j} .
$$

Then, the firm $f$ profits are

$$
\begin{aligned}
\Pi^{f} & =\sum_{k \in G_{f}} M\left(w_{k}-\mu_{k}\right) s_{k}(p)+\sum_{k \in G_{f}} F_{k} \\
& =\sum_{k \in G_{f}} M\left(w_{k}-\mu_{k}\right) s_{k}(p)+\sum_{j=1, . ., J} M\left(p_{j}-w_{j}-c_{j}\right) s_{j}(p)-\sum_{j \notin G_{f}} F_{j}
\end{aligned}
$$

Since producers set fixed fees given those of other producers, the following obtains under resale price maintenance:

$$
\begin{aligned}
\max _{\left\{F_{i}, p_{i}\right\}_{i \in G_{f}}} \Pi^{f} & \Leftrightarrow \max _{\left\{p_{i}\right\}_{i \in G_{f}}} \sum_{k \in G_{f}}\left(w_{k}-\mu_{k}\right) s_{k}(p)+\sum_{j=1, . ., J}\left(p_{j}-w_{j}-c_{j}\right) s_{j}(p) \\
& \Leftrightarrow \max _{\left\{p_{i}\right\}_{i \in G_{f}}} \sum_{k \in G_{f}}\left(p_{k}-\mu_{k}-c_{k}\right) s_{k}(p)+\sum_{k \notin G_{f}}\left(p_{k}-w_{k}-c_{k}\right) s_{k}(p)
\end{aligned}
$$

and with no resale price maintenance

$$
\begin{aligned}
\max _{\left\{F_{i}, w_{i}\right\}_{i \in G_{f}}} \Pi^{f} & \Leftrightarrow \max _{\left\{w_{i}\right\}_{i \in G_{f}}} \sum_{k \in G_{f}}\left(w_{k}-\mu_{k}\right) s_{k}(p)+\sum_{j=1, . ., J}\left(p_{j}-w_{j}-c_{j}\right) s_{j}(p) \\
& \Leftrightarrow \max _{\left\{w_{i}\right\}_{i \in G_{f}}} \sum_{k \in G_{f}}\left(p_{k}-\mu_{k}-c_{k}\right) s_{k}(p)+\sum_{k \notin G_{f}}\left(p_{k}-w_{k}-c_{k}\right) s_{k}(p)
\end{aligned}
$$

Then the first order conditions of the different two part tariff models can be derived very simply. 


\subsection{Matrix Expression of First Order conditions}

\subsubsection{Double marginalization}

The maximization program of retailers gives the following first order conditions:

$$
s_{j}+\sum_{k \in S_{r}}\left(p_{k}-w_{k}-c_{k}\right) \frac{\partial s_{k}}{\partial p_{j}}=0, \quad \text { for all } j \in S_{r} .
$$

Let $I_{r}$ define the $(J \times J)$ ownership matrix of the retailer $r$ that is diagonal and whose element $I_{r}(j, j)$ is equal to one if retailer $r$ sells product $j$ and zero otherwise. Let $S_{p}$ be the market share response matrix to retailer prices, containing the first derivatives of all market shares with respect to all retail prices, i.e.

$$
S_{p} \equiv\left(\begin{array}{ccc}
\frac{\partial s_{1}}{\partial p_{1}} & \cdots & \frac{\partial s_{J}}{\partial p_{1}} \\
\vdots & & \vdots \\
\frac{\partial s_{1}}{\partial p_{J}} & \cdots & \frac{\partial s_{J}}{\partial p_{J}}
\end{array}\right)
$$

In vector notation, previous first order conditions (1) implies that the vector $\gamma$ of retailer $r$ 's margins, i.e. the retail price $p$ minus the wholesale price $w$ minus the marginal cost of distribution $c$, is ${ }^{13}$

$$
\gamma \equiv p-w-c=-\left(I_{r} S_{p} I_{r}\right)^{-1} I_{r} s(p) .
$$

The first order conditions from the maximization program of manufacturers are:

$$
s_{j}+\sum_{k \in G_{f}} \sum_{l=1, . ., J}\left(w_{k}-\mu_{k}\right) \frac{\partial s_{k}}{\partial p_{l}} \frac{\partial p_{l}}{\partial w_{j}}=0, \quad \text { for all } j \in G_{f} .
$$

Consider $I_{f}$ the ownership matrix of manufacturer $f$ that is diagonal and whose element $I_{f}(j, j)$ is equal to one if $j$ is produced by the manufacturer $f$ and zero otherwise. $P_{w}$ the $(J \times J)$ matrix of retail prices responses to wholesale prices, containing the first derivatives of the $J$ retail prices $p$ with respect to the $J^{\prime}$ wholesale prices $w$, is introduced.

$$
P_{w} \equiv\left(\begin{array}{ccccc}
\frac{\partial p_{1}}{\partial w_{1}} & . . & \frac{\partial p_{J^{\prime}}}{\partial w_{1}} & . . & \frac{\partial p_{J}}{\partial w_{1}} \\
\vdots & & \vdots & & \vdots \\
\frac{\partial p_{1}}{\partial w_{J \prime}} & . . & \frac{\partial p_{J^{\prime}}}{\partial w_{J^{\prime}}} & . . & \frac{\partial p_{J}}{\partial w_{J^{\prime}}} \\
0 & . . & 0 & . . & 0 \\
0 & . . & 0 & . . & 0
\end{array}\right)
$$

\footnotetext{
${ }^{13}$ Remark that in all the following, when the inverse of non invertible matrices is used, it means the matrix of generalized inverse is considered, meaning that for example $\left[\begin{array}{ll}2 & 0 \\ 0 & 0\end{array}\right]^{-1}=\left[\begin{array}{cc}1 / 2 & 0 \\ 0 & 0\end{array}\right]$.
} 
Note that the last $J-J^{\prime}$ lines of this matrix are zero because they correspond to private label products for which wholesale prices have no meaning.

The first order conditions (2) can then be expressed in matrix form and the vector of manufacturer's margins is ${ }^{14}$

$$
\Gamma \equiv w-\mu=-\left(I_{f} P_{w} S_{p} I_{f}\right)^{-1} I_{f} s(p)
$$

The derivatives of retail prices with respect to wholesale prices depend on the strategic interactions between manufacturers and retailers. $P_{w}$ can be deduced from the total differentiation of the retailer's first order conditions (1) with respect to wholesale price, i.e. for $j \in S_{r}$ and $k=1, . ., J^{\prime}$

$$
\sum_{l=1, . ., J} \frac{\partial s_{j}(p)}{\partial p_{l}} \frac{\partial p_{l}}{\partial w_{k}}-1_{\left\{k \in S_{r}\right\}} \frac{\partial s_{k}(p)}{\partial p_{j}}+\sum_{l \in S_{r}} \frac{\partial s_{l}(p)}{\partial p_{j}} \frac{\partial p_{l}}{\partial w_{k}}+\sum_{l \in S_{r}}\left(p_{l}-w_{l}-c_{l}\right) \sum_{s=1, . ., J} \frac{\partial^{2} s_{l}(p)}{\partial p_{j} \partial p_{s}} \frac{\partial p_{s}}{\partial w_{k}}=0
$$

Defining $S_{p}^{p_{j}}$ the $(J \times J)$ matrix of the second derivatives of the market shares with respect to retail prices whose element $(l, k)$ is $\frac{\partial^{2} s_{k}}{\partial p_{j} \partial p_{l}}$, i.e.

$$
S_{p}^{p_{j}} \equiv\left(\begin{array}{ccc}
\frac{\partial^{2} s_{1}}{\partial p_{1} \partial p_{j}} & \cdots & \frac{\partial^{2} s_{J}}{\partial p_{1} \partial p_{j}} \\
\vdots & \cdot & \vdots \\
\frac{\partial^{2} s_{1}}{\partial p_{J} \partial p_{j}} & \cdots & \frac{\partial^{2} s_{J}}{\partial p_{J} \partial p_{j}}
\end{array}\right) .
$$

We can write equation (3) in matrix form ${ }^{15}$ :

$$
P_{w}=I_{r} S_{p}\left(I_{r}-\widetilde{I}_{r}\right)\left[S_{p} I_{r}+I_{r} S_{p}^{\prime} I_{r}+\left(S_{p}^{p_{1}} I_{r} \gamma|\ldots| S_{p}^{p_{J}} I_{r} \gamma\right) I_{r}\right]^{-1}
$$

Equation (20) shows that one can express the manufacturer's price cost margins vector $\Gamma=w-\mu$ as depending on the function $s(p)$ by substituting the expression (20) for $P_{w}$ in (18).

As we say in section 3, we can consider like Sudhir(2001) only the direct effect of wholesale price on retail price. In this case, the matrix $P_{w}$ has to be equal to the following

\footnotetext{
${ }^{14}$ Rows of this vector that correspond to private labels are zero.

${ }^{15}$ We use the notation $(a \mid b)$ for horizontal concatenation of $a$ and $b$.
} 
diagonal matrix

$$
\left(\begin{array}{ccccc}
1 & 0 & . . & . . & 0 \\
0 & \ddots & \ddots & \ddots & \vdots \\
\vdots & \ddots & 1 & \ddots & \vdots \\
\vdots & . . & . . & 0 & 0 \\
0 & . . & . . & 0 & 0
\end{array}\right) .
$$

Here too,the price-cost margins of retailers and manufacturers can be computed under this assumption.

The model can also be considered where retailers and/or manufacturers collude perfectly simply by modifying ownership matrices. In the case of perfect price collusion between retailers, the price cost margins of the retail industry can be obtained by replacing the ownership matrices $I_{r}$ in (17) by the identity matrix (the situation being equivalent to a retailer in a monopoly situation). Similarly, the price-cost margins vector for manufacturers can be obtained in the case of perfect collusion by replacing the ownership matrix $I_{f}$ in (18) by a diagonal matrix where diagonal elements are equal to one except for private label goods.

\subsubsection{Two part tariffs}

With resale price maintenance When $w_{k}^{*}=\mu_{k}$, the first order conditions

$$
\sum_{k=1}^{J}\left(p_{k}-\mu_{k}-c_{k}\right) \frac{\partial s_{k}(p)}{\partial p_{j}}+s_{j}(p)=0 \quad \text { for all } j \in G_{f}
$$

become in matrix notation:

$$
I_{f} S_{p}(\gamma+\Gamma)+I_{f} s(p)=0
$$

In the case of private label products, the first order conditions

$$
\sum_{k \in S_{r}}\left(p_{k}-\mu_{k}-c_{k}\right) \frac{\partial s_{k}(p)}{\partial p_{j}}+s_{j}(p)=0 \quad \text { for all } j \in \widetilde{S}_{r}
$$

become in matrix notation: for $r=1, . ., R$

$$
\left(\widetilde{I}_{r} S_{p} I_{r}\right)(\gamma+\Gamma)+\widetilde{I}_{r} s(p)=0
$$

where $\widetilde{I}_{r}$ is the $(J \times J)$ ownership matrix of private label products of retailer $r$. 
We thus obtain a system of equations with (21) and (22) where $\gamma+\Gamma$ is unknown.

$$
\left\{\begin{array}{c}
I_{f} S_{p}(\gamma+\Gamma)+I_{f} s(p)=0 \text { for } f=1, . ., F \\
\left(\widetilde{I}_{r} S_{p} I_{r}\right)(\gamma+\Gamma)+\widetilde{I}_{r} s(p)=0 \text { for } r=1, . ., R
\end{array}\right.
$$

After solving the system (see appendix 8.3), we obtain the expression for the total pricecost margin of all products as a function of demand parameters and of the structure of the industry:

$$
\gamma+\Gamma=-\left(\sum_{r} I_{r} S_{p}^{\prime} \widetilde{I}_{r} S_{p} I_{r}+\sum_{f} S_{p}^{\prime} I_{f} S_{p}\right)^{-1}\left(\sum_{r} I_{r} S_{p}^{\prime} \widetilde{I}_{r}+\sum_{f} S_{p}^{\prime} I_{f}\right) s(p)
$$

Note that in the absence of private label products, this expression would simplify to the case where the total profits of the integrated industry are maximized, that is

$$
\gamma+\Gamma=-S_{p}^{-1} s(p)
$$

because then $\sum_{f} I_{f}=I$.

When wholesale prices $w_{k}^{*}$ are such that $p_{k}^{*}\left(w_{k}^{*}\right)-w_{k}^{*}-c_{k}=0$, the first order conditions

$$
\sum_{k \in G_{f}}\left(p_{k}-\mu_{k}-c_{k}\right) \frac{\partial s_{k}(p)}{\partial p_{j}}+s_{j}(p)+\sum_{k \in\left\{J^{\prime}, . ., J\right\}}\left(p_{k}-\mu_{k}-c_{k}\right) \frac{\partial s_{k}(p)}{\partial p_{j}}=0 \quad \text { for all } j \in G_{f}
$$

become in matrix notation: for all $f=1, . ., F$

$$
\gamma_{f}+\Gamma_{f}=(p-\mu-c)=-\left(I_{f} S_{p} I_{f}\right)^{-1}\left[I_{f} s(p)+I_{f} S_{p} \widetilde{I}(\widetilde{\gamma}+\widetilde{\Gamma})\right]
$$

where $\widetilde{\gamma}+\widetilde{\Gamma}$ is the vector of all private label margins and $\widetilde{I}$ is the ownership matrix for private labels $\left(\widetilde{I}=\sum_{r} \widetilde{I}_{r}\right)$.

In this case, profit maximizing strategic pricing of private labels by retailers is also taken into account by manufacturers when they choose fixed fees and retail prices for their own products in the contract. The prices of private labels chosen by retailers maximize their profit on these private labels and the total price cost margin $\widetilde{\gamma}_{r}+\widetilde{\Gamma}_{r}$ for these private labels will be such that

$$
\widetilde{\gamma}_{r}+\widetilde{\Gamma}_{r} \equiv p-\mu-c=-\left(\widetilde{I}_{r} S_{p} \widetilde{I}_{r}\right)^{-1} \widetilde{I}_{r} s(p)
$$




\section{Without resale price maintenance}

Then the first order conditions

$\sum_{k} \frac{\partial p_{k}}{\partial w_{i}} s_{k}(p)+\sum_{k \in G_{f}}\left[\left(p_{k}-\mu_{k}-c_{k}\right) \sum_{j} \frac{\partial s_{k}}{\partial p_{j}} \frac{\partial p_{j}}{\partial w_{i}}\right]+\sum_{k \notin G_{f}}\left[\left(p_{k}-w_{k}-c_{k}\right) \sum_{j} \frac{\partial s_{k}}{\partial p_{j}} \frac{\partial p_{j}}{\partial w_{i}}\right]=0$

become in matrix notation: for all $i \in G_{f}$

$$
I_{f} P_{w} s(p)+I_{f} P_{w} S_{p} I_{f} \Gamma+I_{f} P_{w} S_{p}(p-w-c)=0 .
$$

This implies that the manufacturer price cost margin is:

$$
\Gamma=\left(I_{f} P_{w} S_{p} I_{f}\right)^{-1}\left[-I_{f} P_{w} s(p)-I_{f} P_{w} S_{p}(p-w-c)\right]
$$

that allows for an estimate of the price-cost margins with demand parameters using (17) to replace $(p-w-c)$ and (20) for $P_{w}$. Remark again that formula (17) directly provides the total price-cost margin obtained by each retailer on his private label.

\subsection{Detailed resolution of system of equations}

Generically we have systems of equations to be solved in the following form

$$
\left\{\begin{array}{c}
A_{f}(\gamma+\Gamma)+B_{f}=0 \\
\text { for } f=1, . ., G
\end{array}\right.
$$

where $A_{f}$ and $B_{f}$ are given matrices.

Solving this system amounts to solve the minimization problem

$$
\min _{\gamma+\Gamma} \sum_{f=1}^{G}\left[A_{f}(\gamma+\Gamma)+B_{f}\right]^{\prime}\left[A_{f}(\gamma+\Gamma)+B_{f}\right]
$$

which leads to the first order conditions

$$
\left(\sum_{f=1}^{G} A_{f}^{\prime} A_{f}\right)(\gamma+\Gamma)-\sum_{f=1}^{G} A_{f}^{\prime} B_{f}=0
$$

that allow the following expression to be found as solution

$$
(\gamma+\Gamma)=\left(\sum_{f=1}^{G} A_{f}^{\prime} A_{f}\right)^{-1} \sum_{f=1}^{G} A_{f}^{\prime} B_{f}
$$




\subsection{Identification method for demand and supply parameters}

Under a given supply model, for a given product $j$, at period $t$, the total price cost margins $\gamma_{j t}+\Gamma_{j t}$ can be expressed as a parametric function of prices and unobserved demand shocks $u_{t}=\left(u_{1 t}, . ., u_{j t}, . ., u_{J t}\right)$ : for example, in the case of two part tariffs with resale price maintenance,

$$
\gamma_{j t}+\Gamma_{j t}=-\left[\left(I_{f} S_{p_{t}} I_{f}\right)^{-1} I_{f} s\left(p_{t}, u_{t}\right)\right]_{j}
$$

where $[.]_{j}$ denotes the $j^{\text {th }}$ row of vector [.].

As marginal cost can be expressed as a function of the observed cost shifter $W_{j t}$, unobserved product specific effects $\omega_{j}$, and unobserved shocks $\eta_{j t}$, we have

$$
C_{j t}=\exp \left(\omega_{j}+W_{j t}^{\prime} \lambda\right) \eta_{j t}
$$

Identification of the price-cost margins relies on the assumption that instruments $Z_{j t}$ satisfy

$$
E\left(Z_{j t} u_{j t}\right)=0
$$

and identification of the cost function relies on the assumption that

$$
E\left(\ln \eta_{j t} W_{j t}\right)=E\left(\ln \eta_{j t} \omega_{j}\right)=0
$$

Adding cost and price cost margin equations, a price equation can also be obtained

$$
p_{j t}+\left[\left(I_{f} S_{p_{t}} I_{f}\right)^{-1} I_{f} s\left(p_{t}, u_{t}\right)\right]_{j}=\exp \left(\omega_{j}+W_{j t}^{\prime} \lambda\right) \eta_{j t}
$$

Identifying the parameters of this price equation would then require specification of the joint law of unobservable shocks $\left(\eta_{j t}, u_{t}\right)$. Thus, our two-step method has the advantage of providing identification of demand and cost parameters under weaker assumptions. In particular no assumptions need to be made on the correlation between unobserved shocks $\left(\eta_{j t}, u_{t}\right)$ 


\subsection{First Stage of Demand Estimation}

\begin{tabular}{lc}
\hline \hline Dependent Variable & $p_{j t}$ \\
\hline Mineral water dummy*wage & -0.0104 \\
& $(-0.83)$ \\
Mineral water dummy*diesel price & 0.00895 \\
& $(6.98)$ \\
& -0.00824 \\
Mineral water dummy* plastic price & $(-2.32)$ \\
\hline $\mathrm{F}(3,1980)$ test & 30.77 \\
\hline Coefficients $\delta_{j}, \gamma_{t}$ not shown \\
\hline \hline$t$ statistics in parentheses
\end{tabular}

Table 12: First Stage of Demand Estimation

\subsection{Additional non-nested tests}

\begin{tabular}{|c|c|c|c|c|c|c|c|c|c|c|c|}
\hline \multicolumn{12}{|c|}{ Vuong (1989) Test Statistic } \\
\hline$\searrow$ & $H_{2}$ & & & & & & & & & & \\
\hline$H_{1}$ & 2 & 3 & 4 & 5 & 6 & 7 & 8 & 9 & 10 & 11 & 12 \\
\hline 1 & $\begin{array}{l}-21.13 \\
(13.58)\end{array}$ & $\begin{array}{r}8.28 \\
(6.96)\end{array}$ & $\begin{array}{c}-2.62 \\
(10.18)\end{array}$ & $\begin{array}{l}-7.53 \\
(4.56)\end{array}$ & $\begin{array}{c}4.36 \\
(6.87)\end{array}$ & $\begin{array}{r}-4.77 \\
(4.09)\end{array}$ & $\begin{array}{r}3.97 \\
(5.62)\end{array}$ & $\begin{array}{l}-14.88 \\
(7.01)\end{array}$ & $\begin{array}{l}-14.57 \\
(6.05)\end{array}$ & $\begin{array}{l}-14.15 \\
(5.93)\end{array}$ & $\begin{array}{l}-0.98 \\
(8.21)\end{array}$ \\
\hline 2 & & $\begin{array}{c}16.73 \\
(10.29)\end{array}$ & $\begin{array}{r}8.17 \\
(5.78)\end{array}$ & $\begin{array}{c}1.58 \\
(9.43)\end{array}$ & $\begin{array}{c}5.57 \\
(8.87)\end{array}$ & $\begin{array}{r}7.90 \\
(9.63)\end{array}$ & $\begin{array}{c}5.33 \\
(10.44)\end{array}$ & $\begin{array}{l}-11.66 \\
(7.11)\end{array}$ & $\begin{array}{l}-12.67 \\
(6.41)\end{array}$ & $\begin{array}{l}-11.54 \\
(6.00)\end{array}$ & $\begin{array}{c}0.19 \\
(12.20)\end{array}$ \\
\hline 3 & & & $\begin{array}{l}-13.77 \\
(16.94)\end{array}$ & $\begin{array}{l}-8.20 \\
(7.28)\end{array}$ & $\begin{array}{c}4.64 \\
(8.27)\end{array}$ & $\begin{array}{r}-8.11 \\
(7.00)\end{array}$ & $\begin{array}{r}4.18 \\
(8.00)\end{array}$ & $\begin{array}{l}-16.68 \\
(10.18)\end{array}$ & $\begin{array}{l}-14.74 \\
(7.94)\end{array}$ & $\begin{array}{l}-14.90 \\
(8.15)\end{array}$ & $\begin{array}{c}-0.60 \\
(10.06)\end{array}$ \\
\hline 4 & & & & $\begin{array}{l}-3.21 \\
(9.68)\end{array}$ & $\begin{array}{c}4.37 \\
(8.57)\end{array}$ & $\begin{array}{c}-0.64 \\
(10.02)\end{array}$ & $\begin{array}{c}4.86 \\
(11.74)\end{array}$ & $\begin{array}{l}-14.21 \\
(7.79)\end{array}$ & $\begin{array}{l}-14.12 \\
(7.39)\end{array}$ & $\begin{array}{l}-13.59 \\
(6.92)\end{array}$ & $\begin{array}{c}-0.55 \\
(12.90)\end{array}$ \\
\hline 5 & & & & & $\begin{array}{c}5.76 \\
(6.42) \\
\end{array}$ & $\begin{array}{r}7.22 \\
(4.72) \\
\end{array}$ & $\begin{array}{r}5.61 \\
(8.18) \\
\end{array}$ & $\begin{array}{c}-1182 \\
(5.27)\end{array}$ & $\begin{array}{l}-14.89 \\
(6.83)\end{array}$ & $\begin{array}{l}-12.77 \\
(5.72) \\
\end{array}$ & $\begin{array}{l}-0.44 \\
(8.55)\end{array}$ \\
\hline 6 & & & & & & $\begin{array}{l}-5.13 \\
(6.72\end{array}$ & $\begin{array}{r}0.11 \\
(5.59)\end{array}$ & $\begin{array}{r}-9.12 \\
(6.40)\end{array}$ & $\begin{array}{l}-10.31 \\
(8.15)\end{array}$ & $\begin{array}{r}-9.73 \\
(7.24)\end{array}$ & $\begin{array}{c}-5.97 \\
(6.39)\end{array}$ \\
\hline 7 & & & & & & & $\begin{array}{r}5.01 \\
(7.48)\end{array}$ & $\begin{array}{l}-14.09 \\
(7.01)\end{array}$ & $\begin{array}{l}-16.21 \\
(7.58)\end{array}$ & $\begin{array}{l}-14.94 \\
(7.00)\end{array}$ & $\begin{array}{l}-0.68 \\
(3.69)\end{array}$ \\
\hline 8 & & & & & & & & $\begin{array}{c}-9.56 \\
(10.56)\end{array}$ & $\begin{array}{c}-10.24 \\
(13.36)\end{array}$ & $\begin{array}{c}-9.54 \\
(10.63)\end{array}$ & $\begin{array}{l}-4.61 \\
(5.05)\end{array}$ \\
\hline 9 & & & & & & & & & $\begin{array}{r}-5.04 \\
(6.89) \\
\end{array}$ & $\begin{array}{r}-2.25 \\
(4.33) \\
\end{array}$ & $\begin{array}{c}4.75 \\
(5.83) \\
\end{array}$ \\
\hline 10 & & & & & & & & & & $\begin{array}{c}5.52 \\
(6.72)\end{array}$ & $\begin{array}{c}7.38 \\
(11.04) \\
\end{array}$ \\
\hline 11 & & & & & & & & & & & $\begin{array}{c}6.11 \\
(7.54)\end{array}$ \\
\hline
\end{tabular}

Table 13: Results of the Vuong Test for the Random Coefficients Logit Model 